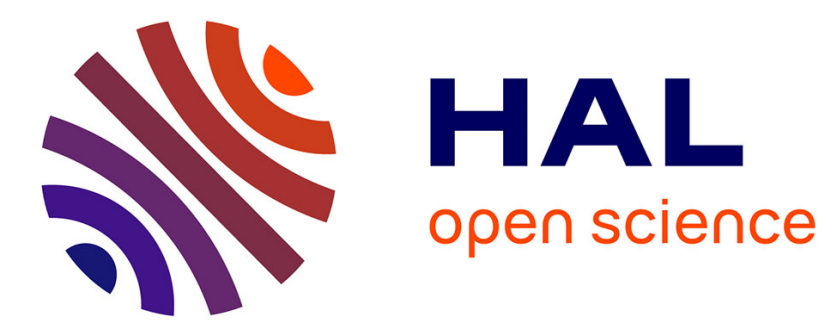

\title{
The sulfo-click reaction and dual labeling of nucleosides
}

Guillaume Clavé, J.J. Vasseur, Michael Smietana

\section{To cite this version:}

Guillaume Clavé, J.J. Vasseur, Michael Smietana. The sulfo-click reaction and dual labeling of nucleosides. Current Protocols in Nucleic Acid Chemistry, 2020, 83 (1), 10.1002/cpnc.120 . hal-03027722

\section{HAL Id: hal-03027722 \\ https://hal.science/hal-03027722}

Submitted on 27 Nov 2020

HAL is a multi-disciplinary open access archive for the deposit and dissemination of scientific research documents, whether they are published or not. The documents may come from teaching and research institutions in France or abroad, or from public or private research centers.
L'archive ouverte pluridisciplinaire HAL, est destinée au dépôt et à la diffusion de documents scientifiques de niveau recherche, publiés ou non, émanant des établissements d'enseignement et de recherche français ou étrangers, des laboratoires publics ou privés. 


\title{
The sulfo-click reaction and dual labeling of nucleosides
}

\section{AUTHOR(S) AND CONTACT INFORMATION:}

Guillaume Clavé - Université de Montpellier, CNRS, ENSCM 34090 Montpellier, France; orcid.org/0000-0001-6401-0935; Email: guillaume.clave@cnrs.fr (Corresponding author)

Jean-Jacques Vasseur - Université de Montpellier, CNRS, ENSCM 34090 Montpellier, France ; orcid.org/0000-0002-4379-6139; Email: jean-jacques.vasseur@umontpellier.fr

Michael Smietana - Université de Montpellier, CNRS, ENSCM 34090 Montpellier, France; orcid.org/0000-0001-8132-7221; Email: michael.smietana@umontpellier.fr (Corresponding author)

\begin{abstract}
:
This unit contains detailed synthetic procedures for the implementation of the sulfo-click reaction to nucleoside derivatives. First, 3'-O-TBDMS-protected nucleosides are converted to their corresponding 4'-thioacide derivatives in three steps. Then, various conjugates are synthetized via a biocompatible and chemoselective coupling procedure using sulfonyl-azides partners. Finally, to illustrate the potential of the sulfo-click reaction a nucleoside bearing two orthogonal azido groups is synthetized and engaged in a one-pot dual labelling through a sulfo-click / copper-catalyzed azide-alkyne cycloaddition (CuAAC) cascade. The high efficiency of the sulfo-click reaction applied to nucleosides opens up new possibilities in the context of bioconjugation.
\end{abstract}

Basic Protocol 1: General protocol for the synthesis of 4'-thioacid-nucleoside derivatives Basic Protocol 2: Implementation of the sulfo-click reaction

Basic Protocol 3: Synthesis of 3'-azido-4'-(carboxamido)ethane-sulfonyl azide-3'-deoxythymidine

Basic Protocol 4: Detailed synthetic procedure for one-pot double-click conjugations

\section{KEYWORDS:}

nucleoside, sulfo-click reaction, bioconjugation, thioacide, sulfonyl azide

\section{INTRODUCTION:}

Click reactions that combine chemoselectivity, bioorthogonality and high efficiency are required to functionalize nucleosides in biocompatible conditions for therapeutic or imaging applications. Moreover, multiple conjugations may be needed in order to access highly functionalized nucleosides. For this purpose orthogonal reactions are required. Although several examples of multiple labelling of nucleic acids have been described in the literature (Meyer et al., 2010; Reisacher et al., 2019; Schoch, Staudt, Samanta, Wiessler, \& Jäschke, 2012; Winz, Linder, Becker, \& Jäschke, 2018), new orthogonal click reactions are needed to expand the potential of multiple labelling strategies. The sulfo-click reaction is an emergent alternative click reaction which involves a thioacid and a sulfonyl azide. The reaction leads to an amide linkage through a stepwise addition-cycloaddition-retro [3+2] cycloaddition sequence, generating elemental sulfur and dinitrogen as byproducts. Thus, the implementation of the sulfo-click reaction on nucleosides requires first the introduction of the thioacid (or sulfonyl azide) function on the nucleosides. In this unit, we report detailed synthetic protocols for the synthesis of 4'-thioacid nucleosides derivatives (Basic Protocol 1). Then, an aqueous biocompatible procedure is described for the implementation of the sulfo-click reaction to these modified nucleosides (Basic Protocol 2). Finally, the synthesis of a nucleoside bearing two orthogonal azides (i.e. a sulfonyl azide and an aliphatic azide) at the $5^{\prime}$ and $3^{\prime}$ positions respectively is described (Basic Protocol 3). The latter undergoes a sequential one-pot dual conjugation procedure via the sulfo-click and the CuAAC reactions leading to a bis-conjugate with high yield (Basic Protocol 4). This protocol based on previously published work (Clavé, Dursun, Vasseur, \& Smietana, 2020) opens the way to a new efficient and easy to implement route to synthetize various doubly functionalized nucleoside derivatives.

\section{STRATEGIC PLANNING}


The protocols presented in this unit are based on several compounds which are not yet commercially available or which are extremely expensive and should therefore be synthesized. Thus, before carrying out the different basic protocols described in this unit, it is necessary to prepare the required reagents according to literature procedures (i.e. compounds 1a-d, 5a-c).

\section{BASIC PROTOCOL 1}

\section{GENERAL PROTOCOL FOR THE SYNTHESIS OF THIOACID NUCLEOSIDE DERIVATIVES}

\section{Introductory paragraph:}

This section provides details of a three-step procedure for the preparation of 4 '-thioacid-nucleosides $4 a-d$ from protected nucleoside derivatives 1a-d (Fig. 1). First, $5^{\prime}-\mathrm{OH}$ nucleosides 1a-d are oxidized with TEMPO/BAIB in aqueous media to obtain carboxylic acids 2 a-d by adapting a procedure described by Epp and Widlanski. (Epp \& Widlanski, 1999). Then, coupling the carboxylic acids 2a-d to 9-fluorenylmethyl thiol (Fm-SH) using BOP as activating reagent in DMF led to the desired $4^{\prime}$-thioesters 3a-d. Finally, both the 9-fluorenylmethyl and the TBDMS groups are cleaved in a single step using TBAF in THF leading to 4'thioacid-nucleosides $4 a-d$ under the form of tetrabutylammonium (TBA) thioacetate salts.

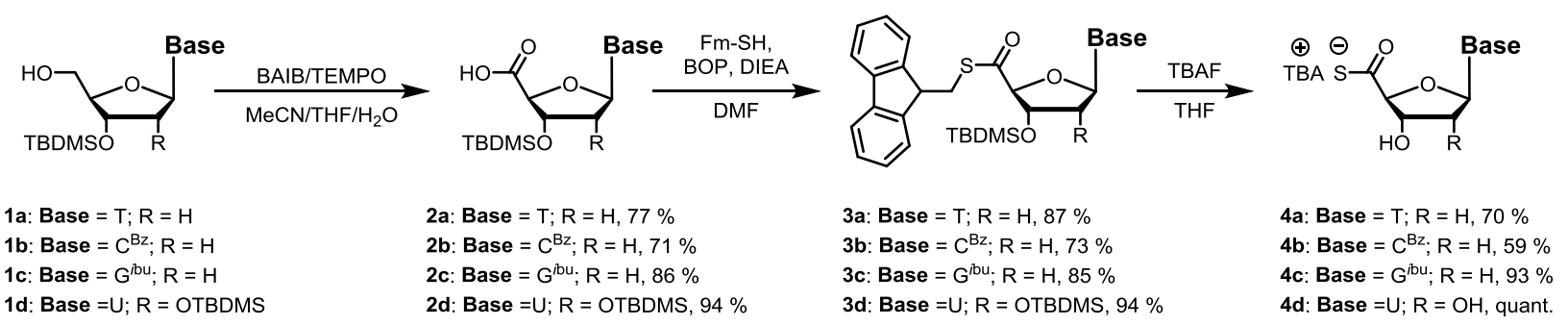

Figure 1 Synthesis of 4'-tetrabutylammonium thioacetate nucleoside derivatives $\mathbf{4 a - d .}$

\section{Materials:}

3'-O-TBDMS-thymidine 1a (Patil, Mane, \& Salunkhe, 1994)

3'-O-TBDMS-N-Bz-cytidine $\mathbf{1 b}$ (Patil et al., 1994)

3'-O-TBDMS-N-iBu-guanosine 1c (Patil et al., 1994)

2', 3'-O-TBDMS-uridine 1d (Zhu, Williams, \& Scott, 2000)

(Diacetoxyiodo)benzene (BAIB, Sigma-Aldrich, CAS Number 3240-34-4)

2,2,6,6-Tetramethylpiperidine 1-oxyl (TEMPO, Sigma-Aldrich, CAS Number 2564-83-2)

9-fluorenylmethanethiol (Fm, Sigma-Aldrich, CAS Number 957753-00-3) (Crich, Sana, \& Guo, 2007)

(Benzotriazol-1-yloxy)tris(dimethylamino)phosphonium hexafluorophosphate (BOP reagent, Sigma-Aldrich, CAS Number 56602-33-6)

$\mathrm{N}, \mathrm{N}$-Diisopropylethylamine, dry (DIEA, Sigma-Aldrich, CAS Number 7087-68-5)

Tetrabutylammonium fluoride solution, $1 \mathrm{M}$ in THF (TBAF, Sigma-Aldrich, CAS Number 429-41-4)

Acetonitrile, analytical grade (MeCN, Sigma-Aldrich, CAS Number 75-05-8)

Dimethyl formamide, dry (DMF, Sigma-Aldrich, CAS Number 68-12-2)

Dichloromethane, analytical grade (DCM, Sigma-Aldrich, CAS Number 75-09-2)

Methanol, analytical grade (MeOH, Sigma-Aldrich, CAS Number 67-56-1)

Ethyl acetate, analytical grade (AcOEt, Sigma-Aldrich, CAS Number 141-78-6)

Cyclohexane, analytical grade (Sigma-Aldrich, CAS Number 110-82-7)

Tetrahydrofurane, analytical grade (THF, Sigma-Aldrich, CAS Number 109-99-9)

Toluene, analytical grade (Sigma-Aldrich, CAS Number 108-88-3) 
Sodium sulfate $\left(\mathrm{Na}_{2} \mathrm{SO}_{4}\right.$, CAS Number 7757-82-6), anhydrous

$0.1 \%$ aqueous trifluoroacetic acid buffer (aq. TFA, $0.1 \%, \mathrm{v} / \mathrm{v}, \mathrm{pH} 2.0$ )

Deionized water

Milli-Q water $18.2 \mathrm{M} \Omega . \mathrm{cm}$ (e.g., from Millipore filtration system)

Brine (saturated aqueous $\mathrm{NaCl}$ solution)

$10 \mathrm{w} \%$ aqueous citric acid solution

Saturated aqueous $\mathrm{NaHCO}_{3}$ solution

$500-, 100-$, and 50-mL round-bottom flasks with ground-glass stoppers

Rubber septa

Magnetic stirrer

Magnetic stir bars

Rotary evaporator

Lyophilizer (freeze-drier) [e.g., FreeZone ${ }^{\circledR}$ bench top freeze dryer]

Vacuum source (water aspirator/membrane pump; vacuum oil pump)

UV lamp, $254 \mathrm{~nm}$

Thin-layer chromatography (TLC) plate (Silica gel 60 F254 aluminum sheets,

Merck)

HPLC system equipped with analytical RP-C18 column (e.g., RP-HPLC Accucore ${ }^{\mathrm{TM}} \mathrm{C} 18$ aQ column, $2.6 \mu \mathrm{m}, 4.6 \times 50 \mathrm{~mm}$ )

Flash chromatography system [e.g., Biotage Isolera $1^{\circledR}$ system]

Pre-packed silica column [e.g., Büchi FlashPure ${ }^{\circledR}$ ]

Stainless steel spatula

Cotton

Fritted glass funnel

Argon gas

\section{Prepare 4'-carboxylic acid-nucleosides 2a-d}

1. Add $8.46 \mathrm{mmol}$ nucleoside 1 to a $500-\mathrm{mL}$ round-bottomed flask equipped with a magnetic stir bar.

For $1 \mathrm{a}: 3.0 \mathrm{~g}$

For $1 \mathrm{~b}: 3.8 \mathrm{~g}$

For $1 \mathrm{c}: 3.8 \mathrm{~g}$

For $1 \mathrm{~d}: 4.0 \mathrm{~g}$

2. Add solvent and stir until complete dissolution.

For 1a : $100 \mathrm{~mL}$ MeCN

For 1b : $100 \mathrm{~mL} M e C N$ and $100 \mathrm{~mL}$ THF

For 1c : $100 \mathrm{~mL}$ MeCN

For 1d : $100 \mathrm{~mL} M e C N$ and $100 \mathrm{~mL}$ THF

3. Add $100 \mathrm{~mL}$ deionized water.

4. In one portion, add $5.45 \mathrm{~g}$ ( $17 \mathrm{mmol}, 2$ equivalents) BAIB. 
5. In one portion, add $265.6 \mathrm{mg}(1.7 \mathrm{mmol}, 0.2$ equivalents) TEMPO.

6. Stir reaction mixture $18 \mathrm{hr}$ at room temperature with an open flask.

7. Monitor reaction by TLC (9:1 DCM/MeOH); TLC analysis indicates the end of the reaction by disappearance of nucleoside $\mathbf{1}$ from the reaction mixture.

If the reaction is not complete and does not seem to progress any more, add BAIB and TEMPO again in the same proportions as many times as necessary every $6 \mathrm{hr}$ until complete disappearance of nucleoside $\mathbf{1}$. Typically, the product $\mathbf{2}$ can partially precipitate in the reaction mixture.

8. Evaporate solvents under reduced pressure using a vacuum pump.

9. Add $50 \mathrm{~mL}$ toluene and co-evaporate using rotary evaporator (three times).

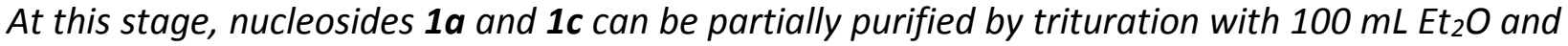
filtration through a fritted glass funnels. Recover and evaporate $\mathrm{Et}_{2} \mathrm{O}$ using rotary evaporator.

10. Purify product $\mathbf{2}$ on a silica gel column. Eluent: $\mathrm{DCM} / \mathrm{MeOH} ; 120$-g flash column, linear gradient $0->20 \%$ in 40 minutes. Pool fractions containing product and evaporate using rotary evaporator.

11. Dry the resulting residue $2 \mathrm{hr}$ in vacuo.

12. Characterize product by TLC, ${ }^{1} \mathrm{H} N M R,{ }^{13} \mathrm{C} N M R$, and HRMS.

For 4'-carboxylic acid-3'-O-TBDMS-thymidine 2a. Yield of white solid $2.41 \mathrm{~g}(77 \%) .{ }^{1} \mathrm{H}$ NMR (400

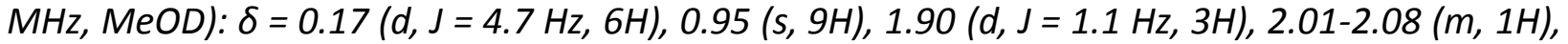
2.23-2.28 (m, $1 \mathrm{H}), 4.41(\mathrm{~s}, 1 \mathrm{H}), 4.7(\mathrm{~d}, \mathrm{~J}=4.4 \mathrm{~Hz}, 1 \mathrm{H}), 6.44\left(\mathrm{dd}, \mathrm{J}_{1}=9.2 \mathrm{~Hz}, \mathrm{~J}_{2}=5.3 \mathrm{~Hz}, 1 \mathrm{H}\right), 8.30$ $(d, J=1.2 \mathrm{~Hz}, 1 \mathrm{H}) \mathrm{ppm} .{ }^{13} \mathrm{C} \mathrm{NMR}(100.6 \mathrm{MHz}, \mathrm{MeOD}): \delta=-4.9,-4.8,12.6,18.8,26.2,40.5,77.5$, 86.8, 87.9, 111.7, 136.6, 152.5, 166.4, 174.2 ppm. HRMS (ESI) m/z: $[\mathrm{M}+\mathrm{H}]^{+}$Calcd for $\mathrm{C}_{16} \mathrm{H}_{26} \mathrm{~N}_{2} \mathrm{O}_{6} \mathrm{Si}$ : 371.1638; found 371.1643. $\operatorname{Rf}(9: 1 \mathrm{DCM} / \mathrm{MeOH})=0.10$.

For 4'-carboxylic acid-3'-O-TBDMS-N-Bz-cytidine $2 \mathrm{~b}$. Yield of white solid $2.76 \mathrm{~g}(71 \%) .{ }^{1} \mathrm{H}$ NMR $(400 \mathrm{MHz}, \mathrm{DMSO}) \delta=0.13(\mathrm{~s}, 6 \mathrm{H}), 0.90(\mathrm{~s}, 9 \mathrm{H}), 1.98-2.05(\mathrm{~m}, 1 \mathrm{H}), 2.36-2.41(\mathrm{~m}, 1 \mathrm{H}), 4.43(\mathrm{~s}, 1 \mathrm{H})$, $4.68(\mathrm{bs}, 1 \mathrm{H}), 6.29\left(\mathrm{dd}, \mathrm{J}_{1}=8.6 \mathrm{~Hz}, \mathrm{~J}_{2}=5.0 \mathrm{~Hz}\right), 7.39(\mathrm{~d}, \mathrm{~J}=7.7 \mathrm{~Hz}, 1 \mathrm{H}), 7.49-8.0(\mathrm{~m}, 5 \mathrm{H}), 8.72(\mathrm{~d}, \mathrm{~J}$ $=7.4 \mathrm{~Hz}, 1 \mathrm{H}) \mathrm{ppm} .{ }^{13} \mathrm{C} \mathrm{NMR}(100.6 \mathrm{MHz}, \mathrm{DMSO}) \delta=-5.0,-4.9,17.7,25.6,40.4,75.5,85.1,87.8$, 96.4, 128.4, 132.7, 133.1, 145.0, 154.3, 163.1, 167.5, 172.0 ppm. HRMS (ESI) m/z: $[\mathrm{M}+\mathrm{H}]^{+}$Calcd for $\mathrm{C}_{22} \mathrm{H}_{30} \mathrm{~N}_{3} \mathrm{O}_{6} \mathrm{Si}:$ : 460.1912; found 460.1908. $\mathrm{Rf}(9: 1 \mathrm{DCM} / \mathrm{MeOH})=0.11$.

For 4'-carboxylic acid-3'-O-TBDMS-N-iBu-guanosine 2c. Yield of white solid $3.29 \mathrm{~g}(86 \%) .{ }^{1} \mathrm{H}$ NMR $(400 \mathrm{MHz}, \mathrm{DMSO}) \delta=0.14(\mathrm{~s}, 6 \mathrm{H}), 0.90(\mathrm{~s}, 9 \mathrm{H}), 1.12(\mathrm{~d}, \mathrm{~J}=6.9 \mathrm{~Hz}, 6 \mathrm{H}), 2.35-2.40(\mathrm{~m}, 1 \mathrm{H}), 2.56-$ $2.63(\mathrm{~m}, 1 \mathrm{H}), 2.73-2.80(\mathrm{~m}, 1 \mathrm{H}), 4.35(\mathrm{bs}, 1 \mathrm{H}), 4.75(\mathrm{bs}, 1 \mathrm{H}), 6.32-6.35(\mathrm{~m}, 1 \mathrm{H}), 8.29(\mathrm{~s}, 1 \mathrm{H}), 11.64$ (bs, 1H), 12.10 (bs, 1H) ppm. ${ }^{13} \mathrm{C} \mathrm{NMR}(100.6 \mathrm{MHz}, \mathrm{DMSO}) \delta=-5.0,-5.0,17.8,18.8,18.9,25.7$, 34.8, 39.4, 75.6, 83.9, 85.3, 120.0, 137.5, 148.3, 148.7, 154.9, 171.8, 180.2 ppm. HRMS (ESI) m/z: $[\mathrm{M}+\mathrm{H}]^{+}$Calcd for $\mathrm{C}_{20} \mathrm{H}_{32} \mathrm{~N}_{5} \mathrm{O}_{6} \mathrm{Si}$ : 466.2122; found 466.2121. $\mathrm{Rf}(9: 1 \mathrm{DCM} / \mathrm{MeOH})=0.02$. 
For 4'-carboxylic acid-2',3'-O-TBDMS-uridine 2d. Yield of white solid $3.87 \mathrm{~g}(94 \%) .{ }^{1} \mathrm{H}$ NMR (400 $\mathrm{MHz}, \mathrm{DMSO}) \delta=-0.07(\mathrm{~s}, 3 \mathrm{H}), 0.02(\mathrm{~s}, 3 \mathrm{H}), 0.09(\mathrm{~s}, 3 \mathrm{H}), 0.11(\mathrm{~s}, 3 \mathrm{H}), 0.81(\mathrm{~s}, 9 \mathrm{H}), 0.89(\mathrm{~s}, 9 \mathrm{H}), 4.17-$ $4.20(\mathrm{~m}, 1 \mathrm{H}), 4.28-4.31(\mathrm{~m}, 2 \mathrm{H}), 5.78\left(\mathrm{dd}, \mathrm{J}_{1}=8.1, \mathrm{~J}_{2}=1.9 \mathrm{~Hz}, 1 \mathrm{H}\right), 5.96(\mathrm{~d}, \mathrm{~J}=6.6 \mathrm{~Hz}), 8.18(\mathrm{~d}, \mathrm{~J}=$ $8.5 \mathrm{~Hz}, 1 \mathrm{H}), 11.41$ (bs, $1 \mathrm{H}) \mathrm{ppm} .{ }^{13} \mathrm{C} N M R(100.6 \mathrm{MHz}, \mathrm{DMSO}) \delta=-5.3,-5.0,-4.8,17.6,17.8,25.6$, 25.7, 74.3, 74.7, 82.4, 87.2, 102.6, 140.3, 150.9, 163.0, 171.9 ppm. HRMS (ESI) m/z: $[M+H]^{+}$Calcd for $\mathrm{C}_{21} \mathrm{H}_{39} \mathrm{~N}_{2} \mathrm{O}_{7} \mathrm{Si}_{2}$ : 487.2296; found 487.2300. $\mathrm{Rf}(9: 1 \mathrm{DCM} / \mathrm{MeOH})=0.15$.

\section{Prepare 4'-(9-fluorenylmethyl thioester)-nucleosides 3a-d}

1. Add $2.0 \mathrm{mmol}$ 4'-carboxylic acid-nucleoside 2 to a $100-\mathrm{mL}$ round-bottomed flask equipped with a magnetic stir bar.

For 2a : $740 \mathrm{mg}$

For $2 \mathbf{b}: 918 \mathrm{mg}$

For $2 \mathrm{c}: 930 \mathrm{mg}$

For $2 \mathrm{~d}: 972 \mathrm{mg}$

2. Add $20 \mathrm{~mL}$ dry DMF and stir until complete dissolution.

3. In one portion, add $658 \mathrm{mg}$ (3.1 mmol, 1.5 equivalents) 9-fluorenylmethanethiol.

4. In one portion, add $1.37 \mathrm{~g}$ (3.1 mmol, 1.5 equivalents) BOP reagent.

5. In one portion, add $715 \mu \mathrm{L}$ (4.1 mmol, 2 equivalents) dry DIEA.

6. Stir reaction mixture $2 \mathrm{hr}$ at room temperature under an argon atmosphere.

7. Monitor reaction by TLC.

For 3a : (9:1 DCM/MeOH) and (8:2 Cyclohexane/AcOEt); TLC (9:1 DCM/MeOH) analysis indicates the end of the reaction by disappearance of $2 a$ from the reaction mixture. TLC (9:1 Cyclohexane/AcOEt) analysis indicates the formation of $\mathbf{3 a}$.

For 3b : (9:1 DCM/MeOH) and (1:1 Cyclohexane/AcOEt); TLC (9:1 DCM/MeOH) analysis indicates the end of the reaction by disappearance of $\mathbf{2} \mathbf{b}$ from the reaction mixture. TLC (9:1 Cyclohexane/AcOEt) analysis indicates the formation of $\mathbf{3 b}$.

For 3c : (9:1 DCM/MeOH) and (3:7 Cyclohexane/AcOEt); TLC (9:1 DCM/MeOH) analysis indicates the end of the reaction by disappearance of $\mathbf{2 c}$ from the reaction mixture. TLC (9:1 Cyclohexane/AcOEt) analysis indicates the formation of $\mathbf{3 c}$.

For 3d : (9:1 DCM/MeOH) and (9:1 Cyclohexane/AcOEt); TLC (9:1 DCM/MeOH) analysis indicates the end of the reaction by disappearance of $\mathbf{2} \mathbf{d}$ from the reaction mixture. TLC (9:1 Cyclohexane/AcOEt) analysis indicates the formation of $\mathbf{3 d}$.

8. Evaporate solvent close to dryness under reduced pressure using a vacuum pump.

The evaporation of DMF require a vacuum $<20$ mbar. 
9. Add $100 \mathrm{~mL}$ AcOEt to the residue and wash with $100 \mathrm{~mL}$ aq. $10 \%$ citric acid, then $100 \mathrm{~mL}$ aq. sat. $\mathrm{NaHCO}_{3}$ and $100 \mathrm{~mL}$ brine. Repeat wash step with brine three times to ensure the elimination of DMF of the organic layer.

10. Dry the organic layer over anhydrous $\mathrm{Na}_{2} \mathrm{SO}_{4}$ and filter off the drying agent on cotton.

11. Purify product 3 on a silica gel column. Eluent: Cyclohexane/AcOEt; $40-\mathrm{g}$ flash column, linear gradient $0->40 \%$ in 40 minutes. Pool fractions containing product and evaporate using rotary evaporator.

12. Dry the resulting residue $2 \mathrm{hr}$ in vacuo.

13. Characterize product by TLC, ${ }^{1} \mathrm{H}$ NMR, ${ }^{13} \mathrm{C} N M R$, and HRMS.

For 4'-(9-fluorenylmethyl thioester)-3'-O-TBDMS-thymidine 3a. Yield of white solid $982 \mathrm{mg}(87 \%)$. $\operatorname{Rf}\left(8: 2\right.$ Cyclohexane/AcOEt) $=0.36 .{ }^{1} \mathrm{H} \mathrm{NMR}\left(400 \mathrm{MHz}, \mathrm{CDCl}_{3}\right): \delta=0.03(\mathrm{~d}, 6 \mathrm{H}), 0.86(\mathrm{~s}, 9 \mathrm{H}), 1.43-$ $1.49(\mathrm{~m}, 1 \mathrm{H}), 1.81(\mathrm{~s}, 3 \mathrm{H}), 1.95-2.00(\mathrm{~m}, 1 \mathrm{H}), 3.78-3.81(\mathrm{~m}, 3 \mathrm{H}), 4.24\left(\mathrm{~s}, 1 \mathrm{H}, \mathrm{H}_{4^{\prime}}\right), 4.28(\mathrm{t}, \mathrm{J}=4.3 \mathrm{~Hz}$, $1 \mathrm{H}, \mathrm{Fm}), 6.39\left(\mathrm{dd}, \mathrm{J}_{1}=9.8 \mathrm{~Hz}, J_{2}=4.6 \mathrm{~Hz}, 1 \mathrm{H}, \mathrm{H}_{1^{\prime}}\right), 7.27-7.73(\mathrm{~m}, 9 \mathrm{H}), 9.02(\mathrm{~s}, 1 \mathrm{H}) \mathrm{ppm} .{ }^{13} \mathrm{C} \mathrm{NMR}$ $\left(100.6 \mathrm{MHz}, \mathrm{CDCl}_{3}\right): \delta=-4.8,-4.7,12.7,18.0,25.0,30.9,38.9,46.8,76.0,86.1,91.3,111.4,119.9$, 120.0, 124.8, 127.2, 128.0, 128.1, 135.8, 141.6, 144.6, 144.7, 150.5, 163.8, 198.7 ppm. HRMS (ESI) $\mathrm{m} / \mathrm{z}:[\mathrm{M}+\mathrm{H}]^{+} \mathrm{Calcd}$ for $\mathrm{C}_{30} \mathrm{H}_{37} \mathrm{~N}_{2} \mathrm{O}_{5} \mathrm{SSi}$ : 565.2192; found 565.2194.

For 4'-(9-fluorenylmethyl thioester)-3'-O-TBDMS-N-Bz-cytidine 3b. Yield of colorless oil $954 \mathrm{mg}$ (73\%). Rf (1:1 Cyclohexane/AcOEt) =0.52. ${ }^{1} \mathrm{H} \mathrm{NMR}\left(400 \mathrm{MHz}, \mathrm{CDCl}_{3}\right): \delta=0.01(\mathrm{~d}, \mathrm{~J}=12.1 \mathrm{~Hz}, 6 \mathrm{H})$, $0.85(\mathrm{~s}, 9 H), 1.27-1.32(\mathrm{~m}, 1 \mathrm{H}), 2.25-2.29(\mathrm{~m}, 1 \mathrm{H}), 3.76-3.87(\mathrm{~m}, 3 H), 4.30-4.32(\mathrm{~m}, 2 H), 6.39-6.42$ $(m, 1 H), 7.29-8.10(m, 15 H) p p m .{ }^{13} \mathrm{C} \mathrm{NMR}\left(100.6 \mathrm{MHz} \mathrm{CDCl}_{3}\right): \delta=-4.8,18.0,25.8,30.9,40.2$, 46.9, 76.2, 88.4, 91.9, 120.0, 120.1, 124.9, 125.0, 127.2, 127.4, 127.7, 128.0, 128.2, 129.2, 133.3, 141.6, 141.7, 144.6, 144.7, 145.3, 162.2, $198.5 \mathrm{ppm}$. HRMS (ESI) m/z: $[M+H]^{+}$Calcd for $\mathrm{C}_{36} \mathrm{H}_{40} \mathrm{~N}_{3} \mathrm{O}_{5} \mathrm{SiS:}$ 654.2458; found 654.2460.

For 4'-(9-fluorenylmethyl thioester)-3'-O-TBDMS-N-iBu-guanosine 3c. Yield of white solid $1.12 \mathrm{~g}$ (85\%). $R f\left(3: 7\right.$ Cyclohexane/AcOEt) $=0.31 .{ }^{1} \mathrm{H} \mathrm{NMR}(400 \mathrm{MHz}, \mathrm{CDCl} 3) \delta=0.02(\mathrm{~s}, 3 \mathrm{H}), 0.03(\mathrm{~s}, 3 \mathrm{H})$, $0.82(\mathrm{~s}, 9 \mathrm{H}), 1.17(\mathrm{dd}, \mathrm{J}=21.1,7.2 \mathrm{~Hz}, 6 \mathrm{H}), 1.70-1.77(\mathrm{~m}, 1 \mathrm{H}), 1.94-1.98(\mathrm{~m}, 1 \mathrm{H}), 2.60$ (hept, $J=$ $7.1 \mathrm{~Hz}, 1 \mathrm{H}), 3.56-3.61(\mathrm{~m}, 1 \mathrm{H}), 3.78-3.86(\mathrm{~m}, 2 \mathrm{H}), 4.19(\mathrm{~s}, 1 \mathrm{H}), 4.24(t, J=4.4 \mathrm{~Hz}, 1 \mathrm{H}), 6.19\left(d d, J_{1}\right.$ $\left.=10.0, J_{2}=5.0 \mathrm{~Hz}, 1 \mathrm{H}\right), 7.25-7.43(\mathrm{~m}, 4 \mathrm{H}), 7.48-7.53(\mathrm{~m}, 3 \mathrm{H}), 7.69-7.75(\mathrm{~m}, 2 \mathrm{H}), 8.98(\mathrm{bs}, 1 \mathrm{H})$, 12.05 (bs, 1H) ppm. ${ }^{13} \mathrm{C} \mathrm{NMR}\left(100.6 \mathrm{MHz}, \mathrm{CDCl}_{3}\right) \delta=-4.9,-4.8,17.9,18.9,19.1,25.7,30.7,36.4$, 39.1, 46.9, 76.1, 84.2, 91.8, 119.8, 120.0, 124.7, 125.2, 127.0, 127.6, 128.0, 128.3, 137.0, 141.3, 141.7, 144.5, 144.8, 147.8, 148.7, 155.7, 178.7, $199.1 \mathrm{ppm}$. HRMS (ESI) m/z: $[\mathrm{M}+\mathrm{H}]^{+}$Calcd for $\mathrm{C}_{34} \mathrm{H}_{42} \mathrm{~N}_{5} \mathrm{O}_{5} \mathrm{SiS}$ : 660.2676; found 660.2680.

For 4'-(9-fluorenylmethyl thioester)-2',3'-O-TBDMS-uridine 3d. Yield of white solid $1.28 \mathrm{~g}$ (94\%). $\operatorname{Rf}\left(9: 1\right.$ Cyclohexane/AcOEt) $=0.30 .{ }^{1} \mathrm{H} \mathrm{NMR}(400 \mathrm{MHz}, \mathrm{CDCl} 3) \delta=-0.09(\mathrm{~s}, 3 \mathrm{H}), 0.01(\mathrm{~s}, 3 \mathrm{H}), 0.02$ $(\mathrm{s}, 3 H), 0.04(\mathrm{~s}, 3 H), 0.83(\mathrm{~s}, 9 H), 0.86(\mathrm{~s}, 9 H), 3.58-3.61(\mathrm{~m}, 1 H), 3.66-3.73(\mathrm{~m}, 2 H), 3.84-3.89(\mathrm{~m}$, $1 H), 4.27$ (bs, $1 H), 4.30(t, J=4.4 \mathrm{~Hz}, 1 \mathrm{H}), 5.65\left(\mathrm{dd}, \mathrm{J}_{1}=8.2, J_{2}=2.2 \mathrm{~Hz}, 1 \mathrm{H}\right), 6.08(\mathrm{~d}, \mathrm{~J}=7.3 \mathrm{~Hz}$, $1 H), 7.30-7.48(m, 5 H), 7.58(t, J=7.3 \mathrm{~Hz}, 2 H), 7.75(t, J=7.7 \mathrm{~Hz}, 2 H), 8.85(s, 1 H) p p m .{ }^{13} \mathrm{C} \mathrm{NMR}$ 
$\left(100.6 \mathrm{MHz}_{\mathrm{CDCl}}\right) \delta=-4.8,-4.7,-4.6,-4.3,17.9,18.0,25.7,25.8,30.9,46.5,74.0,74.9,87.2$, 89.1, 103.2, 119.9, 120.0, 124.7, 124.9, 127.2, 127.4, 128.1, 128.2, 140.2, 141.5, 141.6, 144.5, 144.8, 150.5, 163.0, 198.5 ppm. HRMS (ESI) m/z: $[M+H]^{+}$Calcd for $\mathrm{C}_{35} \mathrm{H}_{49} \mathrm{~N}_{2} \mathrm{O}_{6} \mathrm{SSi}_{2}$ : 681.2850; found 681.2860 .

\section{Prepare 4'-tetrabutylammonium thioacetate-nucleosides 4}

1. Add $329 \mu \mathrm{mol} 3$ to a $50-\mathrm{mL}$ round-bottomed flask equipped with a magnetic stir bar.

For 3a : $186 \mathrm{mg}$

For 3b : $215 \mathrm{mg}$

For 3c : $217 \mathrm{mg}$

For 3d : $224 \mathrm{mg}$

2. Add $8 \mathrm{~mL}$ dry THF and stir until complete dissolution.

3. In one portion, add $1 \mathrm{M}$ TBAF in THF.

For $3 \mathrm{a}: 823 \mu \mathrm{L}(823 \mu \mathrm{mol}, 2.5$ equivalents)

For $3 \mathrm{~b}: 823 \mu \mathrm{L}(823 \mu \mathrm{mol}, 2.5$ equivalents)

For $3 \mathrm{c}: 823 \mu \mathrm{L}(823 \mu \mathrm{mol}, 2.5$ equivalents)

For $3 \mathrm{~d}: 1.15 \mathrm{~mL}$ (1.15 mmol, 3.5 equivalents)

4. Stir reaction mixture $2 \mathrm{hr}$ at room temperature under an argon atmosphere.

5. Monitor reaction by TLC (8:2 Cyclohexane/AcOEt) and RP-HPLC analysis; TLC analysis indicates the disappearance of $\mathbf{3}$ from the reaction mixture. RP-HPLC analysis indicates the formation of $\mathbf{4}$.

RP-HPLC (Accucore ${ }^{\mathrm{TM}} \mathrm{C} 18$ aQ column, $2.6 \mu \mathrm{m}, 4.6 \times 50 \mathrm{~mm}$ ) with $\mathrm{CH}_{3} \mathrm{CN}$ and $0.1 \%$ aqueous trifluoroacetic acid (aq. TFA, $0.1 \%, \mathrm{v} / \mathrm{v}, \mathrm{pH} 2.0$ ) as the eluents [0\% $\mathrm{CH}_{3} \mathrm{CN}(2 \mathrm{~min}$ ), followed by linear gradient from 0 to $100 \%$ ( $25 \mathrm{~min}$ ) of $\mathrm{CH}_{3} \mathrm{CN}$ ] at a flow rate of $1 \mathrm{~mL}$. $\mathrm{min}^{-1}$. Triple UV detection was achieved at 210, 260 and $650 \mathrm{~nm}$ (Fig. 2).

Be aware that the fluorenylmethanethioester is the first protecting group cleaved within ten minutes. The TBDMS group is cleaved after prolonged reaction time. TLC analyzes are difficult to exploit due to the high polarity of the product and the presence of tetrabulylammonium salts. Thus, RP-HPLC analyses are required to ensure the deprotection of the TBDMS groups by observing a single nucleoside peak at 260 nM (Fig 2). Noteworthy, the peak corresponding to the fluvene is variable due to partial precipitation during sample preparation in aqueous media. 


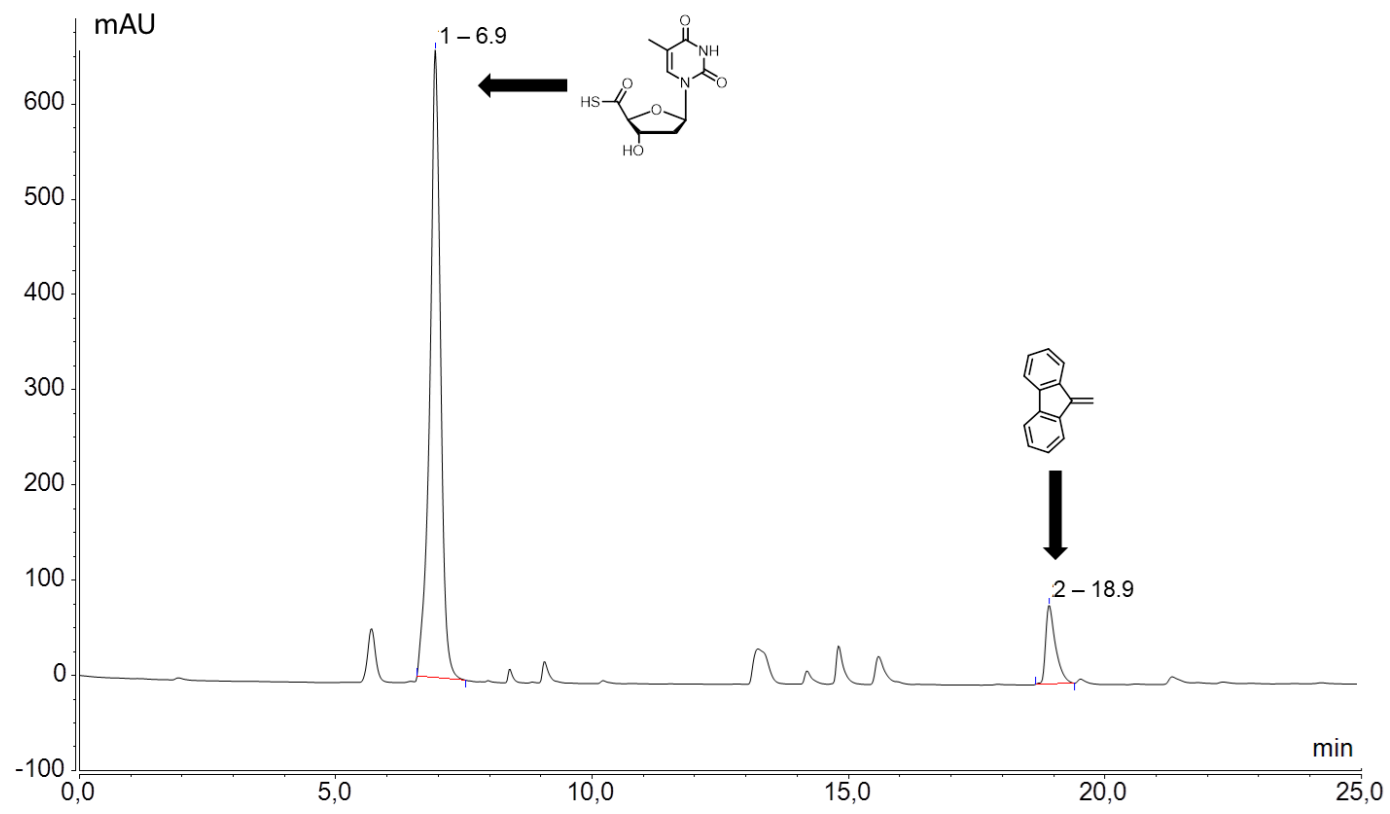

Figure 2.1 Chromatogram of crude deprotection of $3 a$ at $260 \mathrm{~nm} . t_{R}$ (product) $=6.9 \mathrm{~min}, t_{R}$ (fluvene) $=18.9$ $\min$.

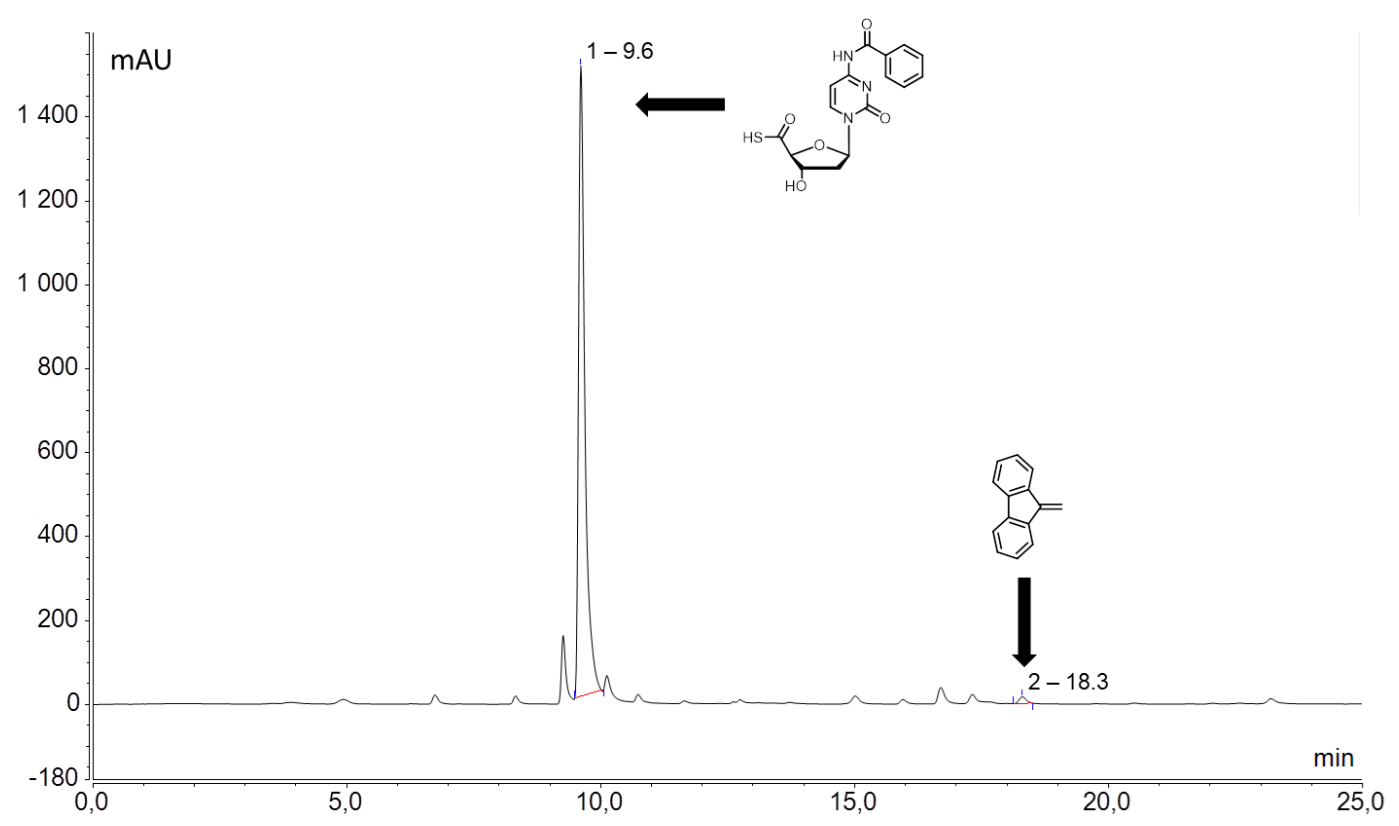

Figure 2.2 Chromatogram of crude deprotection of $\mathbf{3 b}$ at $260 \mathrm{~nm} . t_{R}($ product $)=9.6 \mathrm{~min}, t_{R}$ (fluvene) $=$ $18.3 \mathrm{~min}$. 


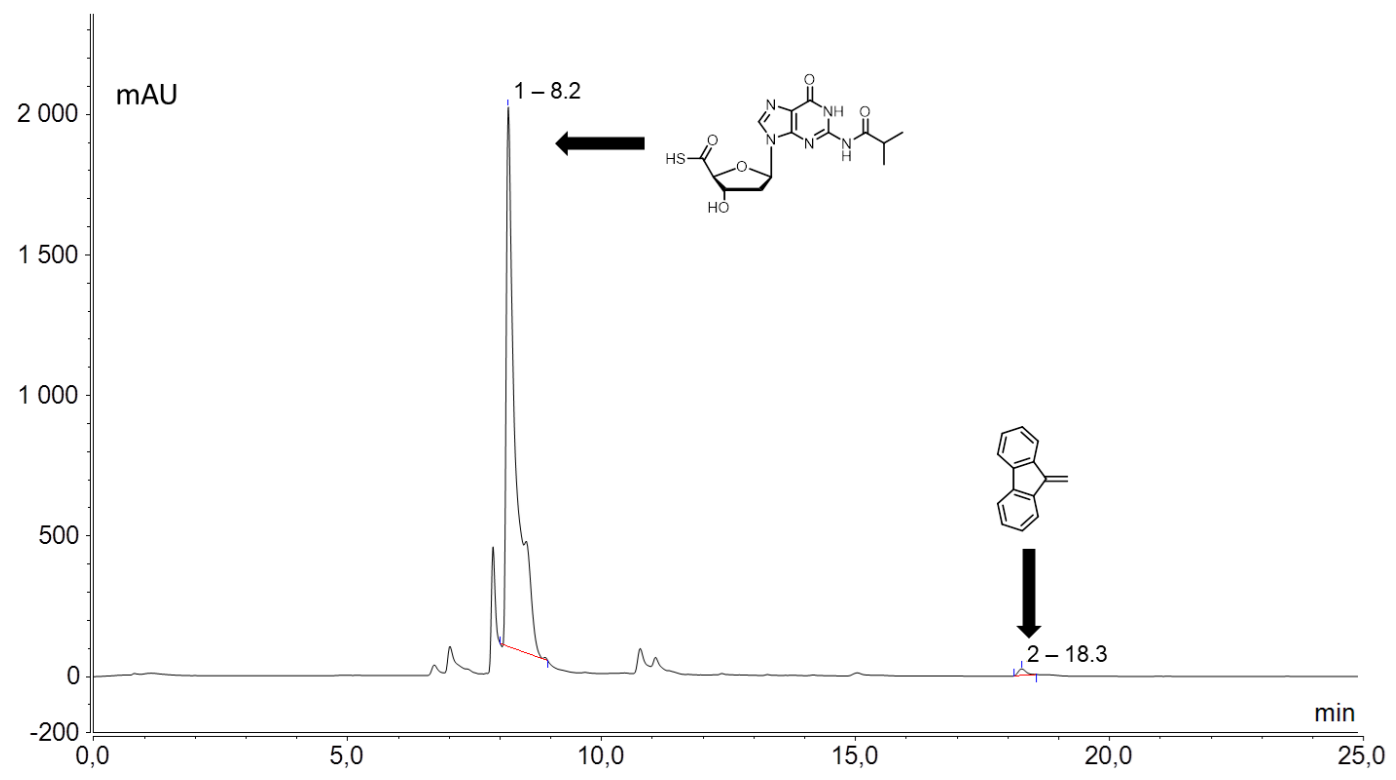

Figure 2.3 Chromatogram of crude deprotection of $3 \mathrm{c}$ at $260 \mathrm{~nm} . t_{R}$ (product) $=8.2 \mathrm{~min}, t_{R}$ (fluvene) $=$ $18.3 \mathrm{~min}$.

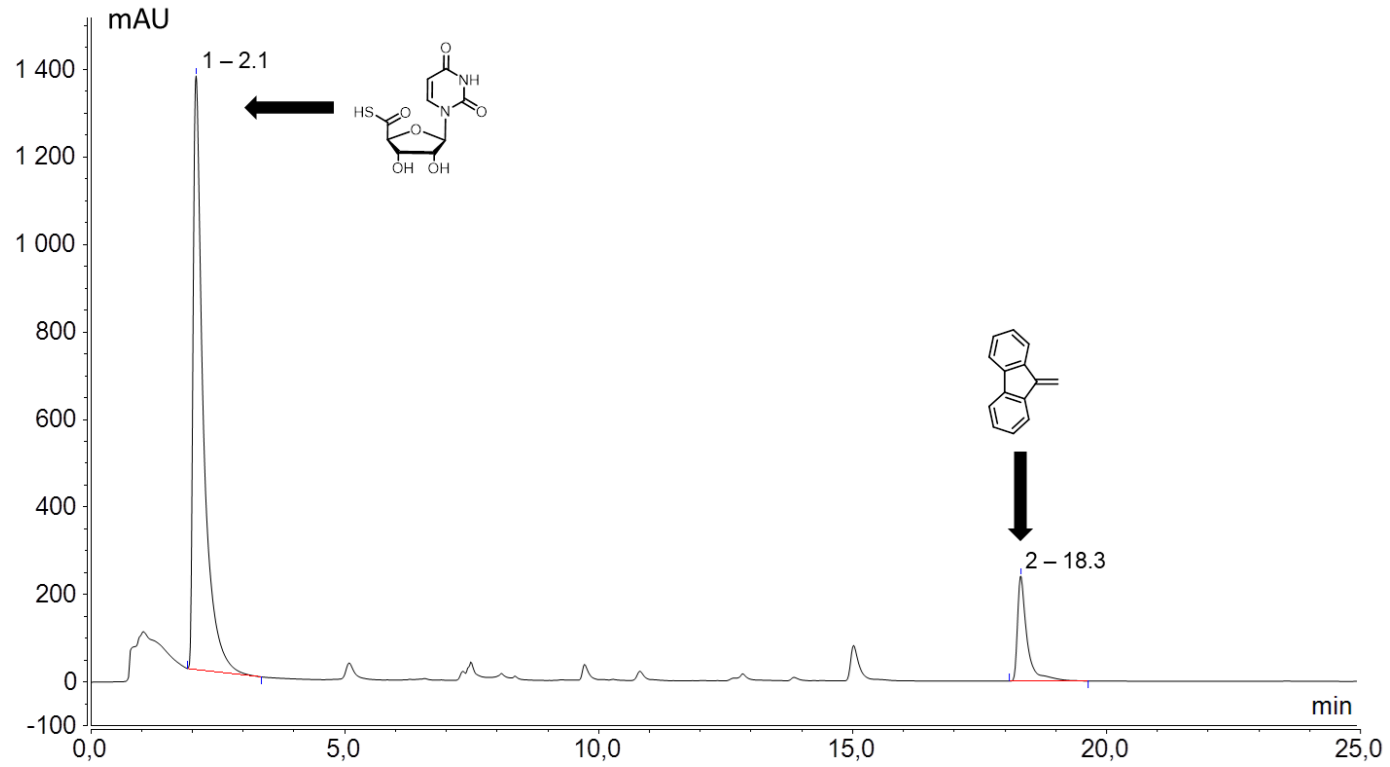

Figure 2.4 Chromatogram of crude deprotection of $3 \mathrm{~d}$ at $260 \mathrm{~nm} . t_{R}$ (product) $=2.1 \mathrm{~min}, t_{R}$ (fluvene) $=$ $18.3 \mathrm{~min}$.

6. Evaporate solvent under reduced pressure using a vacuum pump.

7. Purify product 4 on a silica gel column. Eluent: $\mathrm{DCM} / \mathrm{MeOH} ; 24-\mathrm{g}$ flash column, linear gradient $0->20 \%$ in 40 minutes. Pool fractions containing product and evaporate using rotary evaporator. 
Noteworthy, the product $\mathbf{4}$ is isolated as a tetrabutylammonium thioacetate salt. The latter is stable for month at $-20^{\circ} \mathrm{C}$ but is likely to degrade at room temperature.

8. Dry the resulting residue $2 \mathrm{hr}$ in vacuo.

9. Ad $10 \mathrm{~mL}$ of Milli-Q water and lyophilize.

10. Characterize product by TLC, ${ }^{1} \mathrm{H} N M R,{ }^{13} \mathrm{C} N M R$, and HRMS.

For 4'-tetrabutylammonium thioacetate-thymidine 4a. Yield of white amorphous powder $118 \mathrm{mg}$ (70\%). $\mathrm{Rf}(8: 2 \mathrm{DCM} / \mathrm{MeOH})=0.10 .{ }^{1} \mathrm{H} \mathrm{NMR}\left(400 \mathrm{MHz}, \mathrm{CD}_{3} \mathrm{CN}\right): \delta=0.94(t, J=7.5 \mathrm{~Hz}, 14 \mathrm{H}), 1.29$ $1.38(\mathrm{~m}, 10 \mathrm{H}), 1.56-1.64(\mathrm{~m}, 10 \mathrm{H}), 1.83(\mathrm{~s}, 3 \mathrm{H}), 2.02-2.16(\mathrm{~m}, 2 \mathrm{H}), 3.10-3.15(\mathrm{~m}, 10 \mathrm{H}), 4.26(q, \mathrm{~J}=$ $4.6 \mathrm{~Hz}, 1 \mathrm{H}), 4.46(\mathrm{~d}, \mathrm{~J}=3.7 \mathrm{~Hz}, 1 \mathrm{H}), 6.12(\mathrm{t}, \mathrm{J}=6.0 \mathrm{~Hz}, 1 \mathrm{H}), 8.69(\mathrm{~s}, 1 \mathrm{H}) \mathrm{ppm} .{ }^{13} \mathrm{C} \mathrm{NMR}(100.6 \mathrm{MHz}$, $\left.C D_{3} C N\right): \delta=12.8,13.8,20.3,24.5,39.9,59.2,75.1,86.3,95.1,109.9,139.2,151.7,165.4,213.2$ ppm. HRMS (ESI) m/z: [M+H]+ Calcd for $\mathrm{C}_{10} \mathrm{H}_{11} \mathrm{~N}_{2} \mathrm{O}_{5} \mathrm{~S}$ : 271.0389 ; found 271.0393.

For 4'-tetrabutylammonium thioacetate-N-Bz-cytidine $4 \mathbf{b}$. Yield of white amorphous powder 117 $m g$ (59\%). $R f(8: 2 \mathrm{DCM} / \mathrm{MeOH})=0.12 .{ }^{1} \mathrm{H} \mathrm{NMR}(500 \mathrm{MHz}, \mathrm{MeOD}): \delta=1.01(t, 12 \mathrm{H}, \mathrm{J}=7.4 \mathrm{~Hz})$, 1.36-1.46 (m, 8H), 1.62-1.70 (m, 8H), 1.95-2.01 (m, 1H), 2.47-2.52 (m, 1H), 3.21-3.26 (m, 8H), 4.63 (bs, $1 H), 4.79(s, 1 H), 6.44\left(d d, 1 H, J_{1}=5.4 \mathrm{~Hz}, J_{2}=8.4 \mathrm{~Hz}\right), 7.48-7.66(\mathrm{~m}, 4 \mathrm{H}), 7,98(\mathrm{~d}, \mathrm{~J}=8.0 \mathrm{~Hz}$, 2H), 9,47 (d, J = 7,4 Hz, 1H) ppm. ${ }^{13} \mathrm{C} \mathrm{NMR} \mathrm{(125.7} \mathrm{MHz,} \mathrm{MeOD):} \delta=14.0,20.7,24.8,41.1,59.5$, 77.2, 90.0, 97.3, 98.0, 129.1, 129.8, 134.0, 134.7, 148.4, 157.9, 164.6, 169.0, 217.1 ppm. HRMS (ESI) $\mathrm{m} / \mathrm{z}:[\mathrm{M}-\mathrm{H}]^{-}$Calcd for $\mathrm{C}_{16} \mathrm{H}_{14} \mathrm{~N}_{3} \mathrm{O}_{5} \mathrm{~S}: 360.0654$; found 360.0657 .

For 4'-tetrabutylammonium thioacetate- $N$-iBu-guanosine 4c. Yield of white amorphous powder $186 \mathrm{mg}$ (93\%). $R f(8: 2 \mathrm{DCM} / \mathrm{MeOH})=0.10 .{ }^{1} \mathrm{H} \mathrm{NMR}\left(400 \mathrm{MHz}, C{ }_{3} \mathrm{CN}\right) \delta=0.95(t, J=7.4 \mathrm{~Hz}, 13 \mathrm{H})$, 1.15-1.18 (m, 6H), 1.34 (hex., $J=7.3 \mathrm{~Hz}, 9 H$ ), 1.55-1.63 (m, 9H), 2.30-2.52 (m, 2H), 2.78 (quint., $J$ $=7.0 \mathrm{~Hz}, 1 \mathrm{H}), 3.07-3.11(\mathrm{~m}, 9 \mathrm{H}), 4.45-4.49(\mathrm{~m}, 1 \mathrm{H}), 4.56(\mathrm{~d}, \mathrm{~J}=4.0 \mathrm{~Hz}, 1 \mathrm{H}), 4.70(\mathrm{bs}, 1 \mathrm{H}), 6.22(\mathrm{t}$, $J=6.5 \mathrm{~Hz}, 1 \mathrm{H}), 8.41(\mathrm{~s}, 1 \mathrm{H}), 10.14(\mathrm{bs}, 1 \mathrm{H}), 12.01$ (bs, $1 \mathrm{H}) \mathrm{ppm} .{ }^{13} \mathrm{CNMR}\left(100.6 \mathrm{MHz}, \mathrm{CD}{ }_{3} \mathrm{CN}\right) \delta=$ 13.8, 19.3, 20.3, 24.3, 36.5, 40.2, 59.3, 75.3, 84.5, 95.1, 121.6, 139.6, 149.0, 149.4, 156.6, 181.2, $213.2 \mathrm{ppm}$. HRMS (ESI) $\mathrm{m} / \mathrm{z}:[\mathrm{M}+\mathrm{H}]^{+}$Calcd for $\mathrm{C}_{14} \mathrm{H}_{16} \mathrm{~N}_{5} \mathrm{O}_{5} \mathrm{~S}: 366.0872$; found 366.0873 .

For 4'-tetrabutylammonium thioacetate-uridine 4d. Yield of white amorphous powder $170 \mathrm{mg}$ (quant.). $R f(8: 2 \mathrm{DCM} / \mathrm{MeOH})=0.35 .{ }^{1} \mathrm{H} \mathrm{NMR}\left(400 \mathrm{MHz}, \mathrm{CD}_{3} \mathrm{CN}\right) \delta=0.96(t, \mathrm{~J}=7.3 \mathrm{~Hz}, 14 \mathrm{H}), 1.34$ (hex., $J=7.2 \mathrm{~Hz}, 10 \mathrm{H}), 1.56-1.64(\mathrm{~m}, 10 \mathrm{H}), 3.08-3.12(\mathrm{~m}, 10 \mathrm{H}), 3.87-3.88(\mathrm{~m}, 1 \mathrm{H}), 3.92(\mathrm{bs}, 1 \mathrm{H})$, $4.12(t, J=4.0 \mathrm{~Hz}, 1 \mathrm{H}), 4.54(\mathrm{~d}, J=5.7 \mathrm{~Hz}, 1 \mathrm{H}), 4.90(\mathrm{bs}, 1 \mathrm{H}), 5.59(\mathrm{~d}, \mathrm{~J}=8.1 \mathrm{~Hz}, 1 \mathrm{H}), 5.73(\mathrm{~d}, J=$ $3.5 \mathrm{~Hz}, 1 \mathrm{H}), 8.59(\mathrm{~d}, \mathrm{~J}=8.1 \mathrm{~Hz}, 1 \mathrm{H}), 9.26(\mathrm{bs}, 1 \mathrm{H}) \mathrm{ppm} .{ }^{13} \mathrm{CNMR}\left(100.6 \mathrm{MHz}, C D_{3} C N\right) \delta=13.8,20.3$, 24.3, 59.3, 74.6, 75.6, 90.1, 91.5, 101.9, 142.7, 151.7, 164.5, $212.6 \mathrm{ppm}$. HRMS (ESI) m/z: $[M+H]^{+}$ Calcd for $\mathrm{C}_{9} \mathrm{H}_{11} \mathrm{~N}_{2} \mathrm{O}_{6} \mathrm{~S}$ : 275.0338; found 275.0336. 


\title{
BASIC PROTOCOL 2
}

\section{IMPLEMENTATION OF THE SULFO-CLICK REACTION}

The 4'-tetrabutylammonium thioacetate-nucleosides 4a-d (basic protocol 1 ) and the sulfonyl azide derivatives 5a-c are used to implement the sulfo-click reaction in an aqueous buffered medium without the addition of any other reactant (Fig. 3). For examples of synthesis of sulfonyl azide derivatives see (Clavé et al., 2020; Merkx, Brouwer, Rijkers, \& Liskamp, 2005; Rohmer, Mannuthodikayil, \& Wittmann, 2015; Yim et al., 2010).
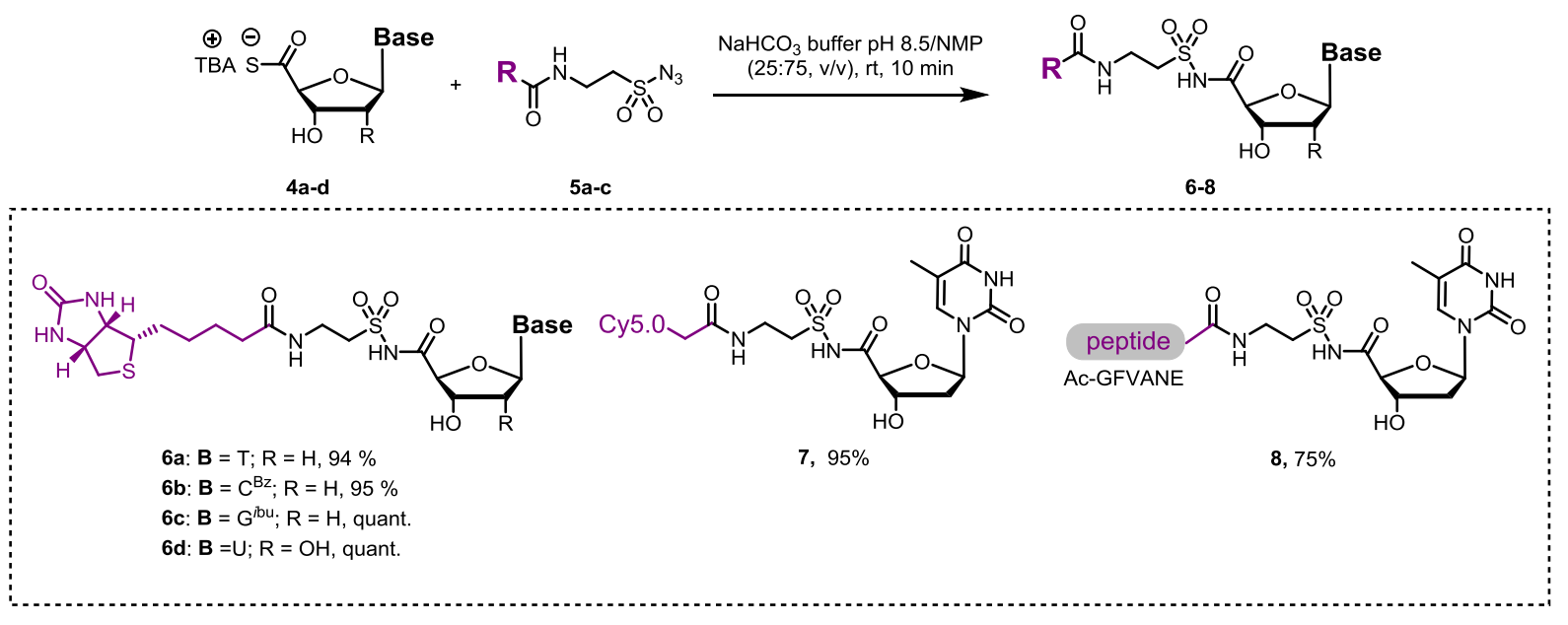

Figure 3 Scope of the sulfo-click reaction applied to nucleosides.

\section{Materials:}

4'-tetrabutylammonium thioacetate-nucleosides 4 a-d (basic protocol 1)

Sulfonyl azide derivatives 5a-c (Clavé et al., 2020)

1-Methyl-2-pyrrolidinone, anhydrous (NMP, Sigma-Aldrich, CAS Number 872-50-4)

Acetonitrile, analytical grade (MeCN, Sigma-Aldrich, CAS Number 75-05-8)

Milli-Q water $18.2 \mathrm{M} \Omega . c m$ (e.g., from Millipore filtration system)

$100 \mathrm{mM} \mathrm{NaHCO}_{3}$ buffer, $\mathrm{pH} 8.5$

$0.1 \%$ aqueous trifluoroacetic acid buffer (aq. TFA, $0.1 \%, \mathrm{v} / \mathrm{v}, \mathrm{pH} 2.0$ )

\author{
1.5-mL Eppendorf Safe-Lock Tubes \\ Vortex (e.g., Vortex-Genie ${ }^{\circledR} 2 \mathrm{~T}$ mixer) \\ Microcentrifuge (Eppendorf) \\ Micropipet [e.g., Gilson ${ }^{\mathrm{TM}}$ PIPETMAN Classic ${ }^{\mathrm{TM}}$ ] \\ $2.6 \mu \mathrm{m}, 4.6 \times 50 \mathrm{~mm}$ ) \\ Lyophilizer (freeze-drier) [e.g., FreeZone ${ }^{\circledR}$ bench top freeze dryer] \\ Vacuum source (water aspirator/membrane pump; vacuum oil pump) \\ Flash chromatography system [e.g., Biotage Isolera $1^{\circledR}$ system] \\ Pre-packed RP-silica column [e.g., Büchi FlashPure ${ }^{\circledR}$ ] \\ Stainless steel spatula
}

HPLC system equipped with analytical RP-C18 column (e.g., RP-HPLC Accucore ${ }^{\mathrm{TM}} \mathrm{C} 18$ aQ column, 
1. Add $15 \mu \mathrm{mol}$ 4'-tetrabutylammonium thioacetate-nucleoside 4 to a first $1.5-\mathrm{mL}$ Eppendorf Safe-Lock Tube.

$$
\begin{aligned}
& \text { For } 4 a: 7.7 \mathrm{mg} \mathrm{4a} \\
& \text { For } 4 \mathbf{b}: 9.0 \mathrm{mg} \mathrm{4b} \\
& \text { For } 4 c: 9.1 \mathrm{mg} \mathrm{4c} \\
& \text { For } 4 \mathbf{d}: 7.7 \mathrm{mg} \mathrm{4d}
\end{aligned}
$$

2. Add $200 \mu \mathrm{L}$ dry NMP and vortex until complete dissolution. Centrifuge the microtube.

3. Add $10 \mu \mathrm{mol}$ sulfonyl azide derivative 5 to a second 1.5-mL Eppendorf Safe-Lock Tube.

For $5 \mathrm{a}: 3.8 \mathrm{mg}$

For $5 b: 9.0 \mathrm{mg}$

For $5 \mathrm{c}: 8.1 \mathrm{mg}$

4. Add $200 \mu \mathrm{L}$ dry NMP and vortex until complete dissolution. Centrifuge the microtube.

5. Mix the two solutions using a micropipet and immediately ad $100 \mu \mathrm{L}$ of $0.1 \mathrm{M}$ aq. $\mathrm{NaHCO}_{3}$ buffer.

6. Vortex for $10 \mathrm{sec}$ and place the microtube at rt without agitation for $10 \mathrm{~min}$.

At this point, you can visually check that the reaction occur after five minutes by observing nitrogen bubbles along with elemental Sulphur precipitates within the mixture.

7. Monitor the reaction by RP-HPLC analysis using the following gradient: (Accucore ${ }^{\mathrm{TM}} \mathrm{C} 18$ aQ column, $2.6 \mu \mathrm{m}, 4.6 \times 50 \mathrm{~mm}$ ) with $\mathrm{CH}_{3} \mathrm{CN}$ and $0.1 \%$ aqueous trifluoroacetic acid (aq. TFA, $0.1 \%$, $\mathrm{v} / \mathrm{v}, \mathrm{pH} 2.0$ ) as the eluents [0\% $\mathrm{CH}_{3} \mathrm{CN}(2 \mathrm{~min}$ ), followed by linear gradient from 0 to $100 \%$ (25 $\min$ ) of $\mathrm{CH}_{3} \mathrm{CN}$ ] at a flow rate of $1 \mathrm{~mL} \cdot \mathrm{min}^{-1}$. Triple UV detection was achieved at 210, 260 and $650 \mathrm{~nm}$.

8. Take up the crude in a $10 \mathrm{~mL}$ syringe; dilute it by withdrawing $9 \mathrm{~mL}$ of aq. TFA, $0.1 \%$ and purify product on a RP-silica gel column. Eluent: Aq. TFA, 0.1\% / MeCN; 12-g flash column, linear gradient $0->40 \%$ in 40 minutes. Pool fractions containing product and lyophilize.

Alternatively, depending on the synthesis scale envisaged and the material available, the product can be purified via semi-preparative RP-HPLC using the same gradient and eluents.

10. Characterize product by RP-HPLC, ${ }^{1} \mathrm{H} N M R,{ }^{13} \mathrm{C} N M R$, and HRMS.

For Biotin-thymidine conjugate 6a. Yield of white amorphous powder $5.5 \mathrm{mg}(94 \%) . T_{R}=8.4 \mathrm{~min}$. ${ }^{1} H$ NMR (400 MHz, DMSO): $\delta=1.23-1.64(m, 6 H), 1.79(s, 3 H), 2.04-2.15(m, 4 H), 2.57(d, J=12.2$ $H z, 1 H), 2.79-2.83\left(d d, 1 H, J_{1}=5.2 \mathrm{~Hz}, J_{2}=12.6 \mathrm{~Hz}\right), 3.01-3.10(\mathrm{~m}, 1 \mathrm{H}), 3.35-3.59(\mathrm{~m}, 4 \mathrm{H}), 4.10-$ $4.13(\mathrm{~m}, 1 \mathrm{H}), 4.28-4.31(\mathrm{~m}, 1 \mathrm{H}), 4.38(\mathrm{~s}, 1 \mathrm{H}), 4.48(\mathrm{bs}, 1 \mathrm{H}), 6.31-6.35(\mathrm{~m}, 1 \mathrm{H}), 6.40(\mathrm{bs}, 2 \mathrm{H}), 7.91$ $(s, 1 H), 8.01(t, J=5.4 \mathrm{~Hz}, 1 \mathrm{H}), 11.4(\mathrm{~s}, 1 \mathrm{H}), 12.2(\mathrm{bs}, 1 \mathrm{H}) \mathrm{ppm} .{ }^{13} \mathrm{C} \mathrm{NMR}(100.6 \mathrm{MHz}, \mathrm{DMSO}): \delta=$ 12.4 , 25.0, 28.0, 28.2, 33.2, 35.0, 38.1, 39.8, 51.5, 55.4, 59.2, 61.0, 73.5, 84.7, 85.8, 109.6, 136.4, 
150.6, 162.7, 163.7, 170.9, 172.4 ppm. HRMS (ESI) m/z: $[M+H]^{+}$Calcd for $\mathrm{C}_{22} \mathrm{H}_{33} \mathrm{~N}_{6} \mathrm{O}_{9} \mathrm{~S}_{2}: 589.1755$; found 589.1750 .

For Biotin-cytidine conjugate 6b. Yield of white amorphous powder $6.4 \mathrm{mg}(95 \%) . T_{R}=10.9 \mathrm{~min}$. ${ }^{1} H$ NMR (500 MHz, DMSO): $\delta=1.23-1.62(m, 6 H), 2.04-2.14(m, 3 H), 2.36-2.42(m, 1 H), 2.55(d$, $J=12.4 \mathrm{~Hz}, 1 \mathrm{H}), 2,79\left(d d, J_{1}=12.4, J_{2}=5.1 \mathrm{~Hz}, 1 \mathrm{H}\right), 3.05-3.09(\mathrm{~m}, 1 \mathrm{H}), 3.42-3.58(\mathrm{~m}, 4 \mathrm{H}), 4.09-$ $4.11(\mathrm{~m}, 1 \mathrm{H}), 4.27-4.29(\mathrm{~m}, 1 H), 4.49(\mathrm{~s}, 1 H), 4.52(\mathrm{~s}, 1 H), 5.82(\mathrm{bs}, 1 H), 6.29-6.32(\mathrm{~m}, 1 H), 6.37$ (bs, $1 H), 6.43(b s, 1 H), 7,42(b s, 1 H), 7.52(t, J=7.8 \mathrm{~Hz}, 2 H), 7.63(t, J=7.4 \mathrm{~Hz}, 1 H), 8.01(d, J=7.5$ $\mathrm{Hz}, 2 \mathrm{H}), 8.06(t, J=5.8 \mathrm{~Hz}, 1 \mathrm{H}), 8.65(\mathrm{~s}, 1 \mathrm{H}), 11.3(\mathrm{bs}, 1 \mathrm{H}), 12.3(\mathrm{bs}, 1 \mathrm{H}) \mathrm{ppm} .{ }^{13} \mathrm{CNMR}(125.7 \mathrm{MHz}$, DMSO): $\delta=25.1,28.0$, 28.2, 33.2, 35.1, 39.1, 39.6, 51.4, 55.4, 59.2, 61.0, 73.8, 85.5, 88.5, 96.5, $128.5,132.9,133.1,145.9,154.6,162.8,163.3,167.4,171.0,172.5 \mathrm{ppm}$. HRMS (ESI) m/z: $[M+H]^{+}$ Calcd for $\mathrm{C}_{28} \mathrm{H}_{36} \mathrm{~N}_{7} \mathrm{O}_{9} \mathrm{~S}_{2}:$ 678.2010; found 678.2008.

For Biotin-guanosine conjugate 6c. Yield of white amorphous powder $6.8 \mathrm{mg}$ (quant.). $T_{R}=9.9$ $\min .{ }^{1} \mathrm{H} \mathrm{NMR}(400 \mathrm{MHz}, \mathrm{DMSO}) \delta=1.12(\mathrm{~d}, \mathrm{~J}=6.8 \mathrm{~Hz}, 6 \mathrm{H}), 1.28-1.63(\mathrm{~m}, 6 \mathrm{H}), 2.03-2.07(\mathrm{~m}, 3 \mathrm{H})$, 2.37-2.42 (m, $1 H), 2.53-2.60(m, 2 H), 2.74-2.82(m, 2 H), 3.05-3.10(m, 1 H), 3.37-3.57(m, 4 H)$, 4.10-4.13 (m, $1 H), 4.28-4.31(\mathrm{~m}, 1 \mathrm{H}), 4.47(\mathrm{~s}, 1 \mathrm{H}), 4.61-4.63(\mathrm{~m}, 1 \mathrm{H}), 6.37-6.40(\mathrm{~m}, 1 \mathrm{H}), 8.02(t, J$ $=5.6 \mathrm{~Hz}, 1 \mathrm{H}), 8.34(\mathrm{~s}, 1 \mathrm{H}), 11.7(\mathrm{~s}, 1 \mathrm{H}), 12.1(\mathrm{bs}, 1 \mathrm{H}) \mathrm{ppm} .{ }^{13} \mathrm{C} \mathrm{NMR}(100.6 \mathrm{MHz}, \mathrm{DMSO}) \delta=18.9$, 25.0, 28.0, 28.2, 33.2, 34.8, 35.1, 38.9, 39.5, 51.5, 55.4, 59.3, 61.1, 73.6, 84.2, 85.3, 119.8, 137.5, $148.3,148.6,154.8,162.8,170.6,172.5,180.2 \mathrm{ppm}$. HRMS (ESI) $\mathrm{m} / \mathrm{z}:[M+H]^{+}$Calcd for $\mathrm{C}_{26} \mathrm{H}_{38} \mathrm{~N}_{9} \mathrm{O}_{9} \mathrm{~S}_{2}: 684.2234 ;$ found 684.2240 .

For Biotin-uridine conjugate 6d. Yield of white amorphous powder $5.9 \mathrm{mg}$ (quant.). $T_{R}=$ $7.6 \mathrm{~min} .{ }^{1} \mathrm{H} N M R(600 \mathrm{MHz}, \mathrm{DMSO}) \delta=1.23-1,63(\mathrm{~m}, 6 \mathrm{H}), 2.05(t, J=7.6 \mathrm{~Hz}, 2 \mathrm{H}), 2.52(d$, $J=9.5 \mathrm{~Hz}, 1 \mathrm{H}), 2.57(\mathrm{~d}, \mathrm{~J}=12.2 \mathrm{~Hz}, 1 \mathrm{H}), 2.81\left(\mathrm{dd}, \mathrm{J}_{1}=12.6 \mathrm{~Hz}, \mathrm{~J}_{2}=5.2 \mathrm{~Hz}, 1 \mathrm{H}\right), 3.07-3.10(\mathrm{~m}$, $1 H)$, 3.35-3.58 ( $m, 4 H), 4.10-4.15(m, 3 H), 4.29-4.31(m, 1 H), 4.42(d, J=2.5 \mathrm{~Hz}, 1 H), 5.76$ $\left(d d, J_{1}=8.3 \mathrm{~Hz}, J_{2}=2.2 \mathrm{~Hz}, 1 \mathrm{H}\right), 5.92(d, J=6.4 \mathrm{~Hz}, 1 \mathrm{H}), 6.39(\mathrm{bs}, 1 \mathrm{H}), 8.00(t, J=5.8 \mathrm{~Hz}$, $1 \mathrm{H}), 8.07(\mathrm{~d}, \mathrm{~J}=8.0 \mathrm{~Hz}, 1 \mathrm{H}), 11.38(\mathrm{~s}, 1 \mathrm{H}) \mathrm{ppm} .{ }^{13} \mathrm{CNMR}(150.6 \mathrm{MHz}, \mathrm{DMSO}) \delta=25.0,28.0$, 28.2, 33.1, 35.0, 40.1, 51.5, 55.4, 59.2, 61.0, 72.8, 72.9, 82.3, 88.0, 102.4, 140.7, 150.9, 162.7, 163.0, 170.8, $172.5 \mathrm{ppm}$. HRMS (ESI) m/z: $[M+H]^{+}$Calcd for $\mathrm{C}_{21} \mathrm{H}_{31} \mathrm{~N}_{6} \mathrm{O}_{10} \mathrm{~S}_{2}$ : 591.1538; found 591.1536.

For Cy5.0-thymidine conjugate 7. Yield of deep blue amorphous powder $10.6 \mathrm{mg}$ (95\%). $T_{R}=10.8$ min. HRMS (ESI) m/z: [M+H] Calcd for $\mathrm{C}_{45} \mathrm{H}_{57} \mathrm{~N}_{6} \mathrm{O}_{14} \mathrm{~S}_{3}$ : 1001.3095; found 1001.3095.

Cy5.0-thymidine conjugate 7 was only characterized by RP-HPLC and HRMS analysis.

Hexapeptide-thymidine conjugate 8. Yield of white amorphous powder $7.6 \mathrm{mg}(75 \%) . T_{R}=$ $9.3 \mathrm{~min} .{ }^{1} \mathrm{H} N \mathrm{NMR}(500 \mathrm{MHz}, \mathrm{DMSO}): \delta=0.82-0.86(\mathrm{~m}, 6 \mathrm{H}), 1.20-1.23(\mathrm{~m}, 4 \mathrm{H}), 1.68-1.75$ $(m, 1 H), 1.78(\mathrm{~s}, 3 H), 1.81(\mathrm{~s}, 3 H), 2.06-2.16(\mathrm{~m}, 6 \mathrm{H}), 2.43-2.47(\mathrm{~m}, 1 \mathrm{H}), 2.52-2.58(\mathrm{~m}, 1 \mathrm{H})$, 2.74-2.79 (m, $1 H), 2.97-3.01(m, 1 H), 3.52-3.69(m, 4 H), 4.03-4.08(m, 1 H), 4.13-4.16(m$, $1 H), 4.25-4.31(\mathrm{~m}, 1 \mathrm{H}), 4.38(\mathrm{~s}, 1 \mathrm{H}), 4.43-4.48(\mathrm{~m}, 2 \mathrm{H}), 4.57-4.62(\mathrm{~m}, 1 \mathrm{H}), 5.75(\mathrm{bs}, 1 \mathrm{H})$, 6.32-6.35 (m, 1H), $7.00(\mathrm{~s}, 1 H), 7.11(\mathrm{~s}, 1 \mathrm{H}), 7.16-7.25(\mathrm{~m}, 5 H), 7.37(\mathrm{~s}, 1 H), 7.47(\mathrm{~s}, 1 \mathrm{H})$, 7.92-8.10 (m 7H), $11.4(\mathrm{~s}, 1 H) \mathrm{ppm} .{ }^{13} \mathrm{CNMR}(125.7 \mathrm{MHz}, \mathrm{DMSO}): \delta=12.5,18.0,18.3,19.3$, 
22.4, 27.5, 30.5, 31.7, 33.3, 36.9, 37.5, 38.1, 41.9, $48.249 .8,51.4,52.1,53.6,57.6,73.6$, 84.7, 85.8, 109.7, 126.3, 128.0, 129.3, 136.4, 137.7, 150.7, 163.7, 168.9, 169.6, 170.6, 170.9, 171.0, 171.8, 172.0, 172.2, $173.2 \mathrm{ppm}$. HRMS (ESI) m/z: $[\mathrm{M}+\mathrm{H}]^{+}$Calcd for $\mathrm{C}_{42} \mathrm{H}_{61} \mathrm{~N}_{12} \mathrm{O}_{16} \mathrm{~S}:$ 1021.4049; found 1021.4057 . 


\section{BASIC PROTOCOL 3}

\section{SYNTHESIS OF 3'-AZIDO-4'-(CARBOXAMIDO)ETHANE-SULFONYL AZIDE-3'-DEOXYTHYMIDINE}

The protocol of this section describes in details the synthesis of the bis-azido thymidine 11 . The presented reaction strategy started with commercially available azidothymidine 9 which underwent oxydation at the 5'-OH with TEMPO/BAIB in a mixture of $\mathrm{MeCN}$ and water to obtain compound 10 (Fig. 4). Then, the coupling of carboxylic acid $\mathbf{1 0}$ to 2-aminoethane-sulfonyl azide using BOP reagent in DMF led to the desired bis-azido thymidine $\mathbf{1 1}$ (Fig. 4).
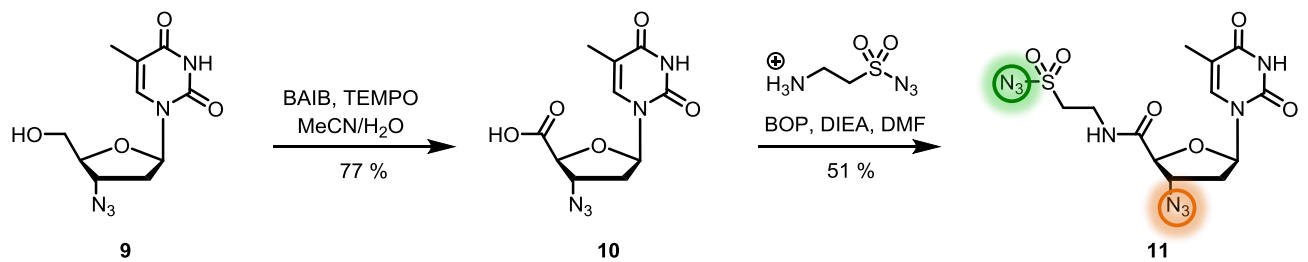

Figure 4 Synthesis of 3'-azido-4'-(carboxamido)ethane-sulfonyl azide-3'-deoxythymidine 11.

\section{Materials:}

3'-Azido-3'-deoxythymidine (AZT, Sigma-Aldrich, CAS Number 30516-87-1)

2-aminoethane-sulfonyl azide hydrobromide (Brouwer, Merkx, Dabrowska, Rijkers, \& Liskamp, 2006)

(Diacetoxyiodo)benzene (BAIB, Sigma-Aldrich, CAS Number 3240-34-4)

2,2,6,6-Tetramethylpiperidine 1-oxyl (TEMPO, Sigma-Aldrich, CAS Number 2564-83-2)

(Benzotriazol-1-yloxy)tris(dimethylamino)phosphonium hexafluorophosphate (BOP reagent, Sigma-Aldrich, CAS Number 56602-33-6)

N,N-Diisopropylethylamine, dry (DIEA, Sigma-Aldrich, CAS Number 7087-68-5)

Acetonitrile, analytical grade (MeCN, Sigma-Aldrich, CAS Number 75-05-8)

Dimethyl formamide, dry (DMF, Sigma-Aldrich, CAS Number 68-12-2)

Dichloromethane, analytical grade (DCM, Sigma-Aldrich, CAS Number 75-09-2)

Methanol, analytical grade (MeOH, Sigma-Aldrich, CAS Number 67-56-1)

Ethyl acetate, analytical grade (AcOEt, Sigma-Aldrich, CAS Number 141-78-6)

Toluene, analytical grade (Sigma-Aldrich, CAS Number 108-88-3)

Sodium sulfate ( $\mathrm{Na}_{2} \mathrm{SO}_{4}$, Sigma-Aldrich, CAS Number 7757-82-6), anhydrous

Deionized water

Brine (saturated aqueous $\mathrm{NaCl}$ solution)

$10 \mathrm{w} \%$ aqueous citric acid solution

Saturated aqueous $\mathrm{NaHCO}_{3}$ solution

20- and $10-\mathrm{mL}$ round-bottom flasks with ground-glass stoppers

Rubber septa

Magnetic stirrer

Magnetic stir bars

Rotary evaporator

Vacuum source (water aspirator/membrane pump; vacuum oil pump)

UV lamp, $254 \mathrm{~nm}$

Thin-layer chromatography (TLC) plate (Silica gel 60 F254 aluminum sheets, Merck) 
Flash chromatography system [e.g., Biotage Isolera $1^{\circledR}$ system]

Pre-packed silica column [e.g., Büchi FlashPure ${ }^{\circledR}$ ]

Stainless steel spatula

Cotton

Argon gas

\section{Prepare 4'-carboxylic acid-3'-azido-3'-deoxythymidine 10}

1. Add $115 \mathrm{mg}(430 \mu \mathrm{mol})$ AZT 9 to a $20-\mathrm{mL}$ round-bottomed flask equipped with a magnetic stir bar.

2. Add $5 \mathrm{~mL}$ MeCN and stir until complete dissolution.

3. Add $5 \mathrm{~mL}$ deionized water.

4. In one portion, add $277 \mathrm{mg}(860 \mu \mathrm{mol}, 2$ equivalents) BAIB.

5. In one portion, add $13 \mathrm{mg}(86 \mu \mathrm{mol}, 0.2$ equivalents) TEMPO.

6. Stir reaction mixture $18 \mathrm{hr}$ at room temperature with an open flask.

7. Monitor reaction by TLC (9:1 DCM/MeOH); TLC analysis indicates the end of the reaction by disappearance of nucleoside 9 from the reaction mixture.

If the reaction is not complete and does not seem to progress any more, add BAIB and TEMPO again in the same proportions as many times as necessary every $6 \mathrm{hr}$ until complete disappearance of AZT 9.

8. Evaporate solvents under reduced pressure using a vacuum pump.

9. Add $10 \mathrm{~mL}$ toluene and co-evaporate using rotary evaporator (three times).

10. Purify product on a silica gel column. Eluent: $\mathrm{DCM} / \mathrm{MeOH} ; 24-\mathrm{g}$ flash column, linear gradient $0->20 \%$ in 40 minutes. Pool fractions containing product and evaporate using rotary evaporator.

11. Dry the resulting residue $2 \mathrm{hr}$ in vacuo.

13. Characterize product 10 by TLC, ${ }^{1} \mathrm{H}$ NMR, ${ }^{13} \mathrm{C}$ NMR, and HRMS.

Yield of white powder $93 \mathrm{mg}(77 \%) . R f(9: 1 \mathrm{DCM} / \mathrm{MeOH})=0.03 .{ }^{1} \mathrm{H} \mathrm{NMR}(400 \mathrm{MHz}, \mathrm{MeOD}) \delta=$ $1.89(\mathrm{~s}, 3 \mathrm{H}), 2.26-2.45(\mathrm{~m}, 1 \mathrm{H}), 4.52(\mathrm{~d}, \mathrm{~J}=2,8 \mathrm{~Hz}, 1 \mathrm{H}), 4.62-4.65(\mathrm{~m}, 1 \mathrm{H}), 6.26-6.29(\mathrm{~m}, 1 \mathrm{H}), 8.08$ (s, 1H) ppm. ${ }^{13} \mathrm{C} N M R(100.6 \mathrm{MHz}, \mathrm{MeOD}) \delta=12.6,37.3,65.5,83.0,87.8,111.7,138.3,152.3$, 166.3, 173.2 ppm. HRMS (ESI) m/z: [M+H] $]^{+}$Calcd for $\mathrm{C}_{10} \mathrm{H}_{12} \mathrm{~N}_{5} \mathrm{O}_{5}$ : 282.0833; found 282.0851 . 


\section{Prepare 3'-azido-4'-(carboxamido)ethane-sulfonyl azide-3'-deoxythymidine 11}

1. Add $60 \mathrm{mg}(214 \mu \mathrm{mol})$ 4'-carboxylic acid-3'-azido-3'deoxythymidine $\mathbf{1 0}$ to a 10 -mL roundbottomed flask equipped with a magnetic stir bar.

2. Add $1 \mathrm{~mL}$ dry DMF and stir until complete dissolution.

3. In one portion, add $74 \mathrm{mg}(321 \mu \mathrm{mol}, 1.5$ equivalents) 2-aminoethane-sulfonyl azide hydrobromide.

4. In one portion, add $142 \mathrm{mg}$ ( $321 \mu \mathrm{mol}, 1.5$ equivalents) BOP reagent.

5. In one portion, add $75 \mu \mathrm{L}(428 \mu \mathrm{ol}, 2$ equivalents) dry DIEA.

6. Stir reaction mixture $2 \mathrm{hr}$ at room temperature under an argon atmosphere.

7. Monitor reaction by TLC (9:1 DCM/MeOH) and (5:5 DCM/AcOEt); TLC (9:1 DCM/MeOH) analysis indicates the end of the reaction by disappearance of 4'-carboxylic acid-3'-azido-3'deoxythymidine 10 from the reaction mixture. TLC (5:5 DCM/AcOEt) analysis indicates the formation of 3'-azido-4'-(carboxamido)ethane-sulfonyl azide-3'-deoxythymidine $\mathbf{1 1 .}$

8. Add $50 \mathrm{~mL}$ AcOEt to the crude and wash with $50 \mathrm{~mL}$ aq. $10 \%$ citric acid, then $50 \mathrm{~mL}$ aq. sat. $\mathrm{NaHCO}_{3}$ and $50 \mathrm{~mL}$ brine. Repeat wash step with brine three times to ensure the elimination of DMF of the organic layer.

9. Dry the organic layer over anhydrous $\mathrm{Na}_{2} \mathrm{SO}_{4}$ and filter off the drying agent on cotton.

10. Purify product on a silica gel column. Eluent: DCM/AcOEt; 12 -g flash column, linear gradient $0->40 \%$ in 40 minutes. Pool fractions containing product and evaporate using rotary evaporator.

11. Dry the resulting residue $2 \mathrm{hr}$ in vacuo.

12. Characterize product 11 by TLC, ${ }^{1} \mathrm{H}$ NMR, ${ }^{13} \mathrm{C}$ NMR, and HRMS.

Yield of white powder $45 \mathrm{mg}$ (51\%). $R f(9: 1 \mathrm{DCM} / \mathrm{AcOEt})=0.15 .{ }^{1} \mathrm{H} \mathrm{NMR}(400 \mathrm{MHz}, \mathrm{CDCl}): \delta=$ $1.91(\mathrm{~s}, 3 \mathrm{H}), 2.21-2.27(\mathrm{~m}, 1 \mathrm{H}), 2.59-2.66(\mathrm{~m}, 1 \mathrm{H}), 3.56-4.04(\mathrm{~m}, 4 \mathrm{H}), 4.36(\mathrm{~d}, \mathrm{~J}=3.6 \mathrm{~Hz}, 1 \mathrm{H}), 4.56$ (quin., $J=3.7 \mathrm{~Hz}), 6.03(t, J=6.8 \mathrm{~Hz}, 1 \mathrm{H}), 7.19(\mathrm{~s}, 1 \mathrm{H}), 7.68(t, J=5.8 \mathrm{~Hz}, 1 \mathrm{H}), 9.56(\mathrm{~s}, 1 \mathrm{H}) \mathrm{ppm} .{ }^{13} \mathrm{C}$ NMR (100.6 MHz, $\left.\mathrm{CDCl}_{3}\right): \delta=12.4,34.0,35.2,54.3,63.6,83.4,88.9,112.2,137.6,150.8,163.9$, 170.0 ppm. HRMS (ESI) m/z: $[\mathrm{M}+\mathrm{H}]^{+}$Calcd for $\mathrm{C}_{12} \mathrm{H}_{16} \mathrm{~N}_{9} \mathrm{O}_{6} \mathrm{~S}: 414.0939$; found 414.0956 . 


\section{BASIC PROTOCOL 4}

\section{DETAILED SYNTHETIC PROCEDURE FOR ONE-POT DOUBLE CLICK CONJUGATIONS}

The 3'-azido-4'-(carboxamido)ethane-sulfonyl azide-3'-deoxythymidine $\mathbf{1 1}$ (basic protocol 4) is subjected to a biocompatible onepot double-labelling procedure (Fig. 5). The sulfonyl azide moiety is first engaged in a sulfo-click reaction with 4'tetrabutylammonium thioacetate-uridine $\mathbf{4 d}$ (basic protocol 1 ) in a buffered aqueous media without the addition of any other reactant. Once the reaction is completed, the biotin bearing a terminal alkyne is used to perform a CuAAC reaction leading to the desired bis-conjugate 13 .

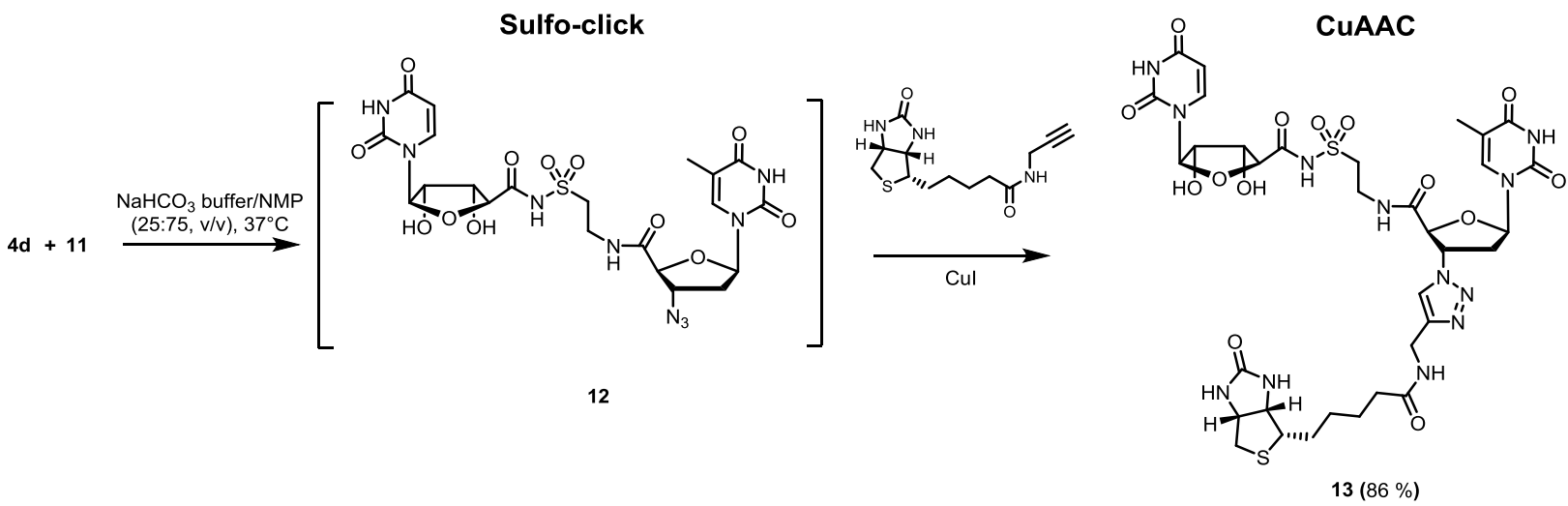

Figure 5 Synthesis of the deoxythymidine bis-conjugate 13.

\section{Materials:}

$4^{\prime}$-tetrabutylammonium thioacetate-uridine $\mathbf{4 d}$ (basic protocol 1 )

3'-azido-4'-(carboxamido)ethane-sulfonyl azide-3'-deoxythymidine 11 (basic protocol 4)

1-Methyl-2-pyrrolidinone, anhydrous (Sigma-Aldrich, CAS Number 872-50-4)

Acetonitrile, analytical grade (MeCN, Sigma-Aldrich, CAS Number 75-05-8)

Milli-Q water $18.2 \mathrm{M} \Omega . c m$ (e.g., from Millipore filtration system)

$100 \mathrm{mM} \mathrm{NaHCO}_{3}$ buffer, $\mathrm{pH} 8.5$

$0.1 \%$ aqueous trifluoroacetic acid buffer (aq. TFA, $0.1 \%, \mathrm{v} / \mathrm{v}, \mathrm{pH} 2.0$ )

$\mathrm{N}, \mathrm{N}$-Diisopropylethylamine, dry (DIEA, Sigma-Aldrich, CAS Number 7087-68-5)

Copper(I) iodide (Cul, Sigma-Aldrich, CAS Number 7681-65-4)

Biotin alkyne (Lumiprobe, CAS Number 773888-45-2)

\section{5-mL Eppendorf Safe-Lock Tubes}

Vortex (e.g., Vortex-Genie ${ }^{\circledR} 2 \mathrm{~T}$ mixer)

Microcentrifuge (Eppendorf)

Micropipet [e.g., Gilson ${ }^{\mathrm{TM}}$ PIPETMAN Classic ${ }^{\mathrm{TM}}$ ]

HPLC system equipped with analytical RP-C18 column (e.g., RP-HPLC Accucore ${ }^{\mathrm{TM}} \mathrm{C} 18$ aQ column, $2.6 \mu \mathrm{m}, 4.6 \times 50 \mathrm{~mm}$ )

Lyophilizer (freeze-drier) [e.g., FreeZone ${ }^{\circledR}$ bench top freeze dryer]

Vacuum source (water aspirator/membrane pump; vacuum oil pump)

Flash chromatography system [e.g., Biotage Isolera $1^{\circledR}$ system]

Pre-packed RP-silica column [e.g., Büchi FlashPure ${ }^{\circledR}$ ] 
Stainless steel spatula

Perform the sulfoclick reaction

1. Add $5 \mathrm{mg}(12 \mu \mathrm{mol})$ 3'-azido-4'-(carboxamido)ethane-sulfonyl azide-3'-deoxythymidine $\mathbf{1 1}$ to a 1.5-mL Eppendorf Safe-Lock Tube.

2. Add $200 \mu \mathrm{L}$ dry NMP and vortex until complete dissolution. Centrifuge the microtube.

3. Add $9.3 \mathrm{mg}$ (18 $\mu \mathrm{mol}, 1.5$ equivalent) 4'-tetrabutylammonium thioacetate-uridine $4 \mathrm{~d}$ to a 1.5 $\mathrm{mL}$ Eppendorf Safe-Lock Tube.

4. Add $200 \mu \mathrm{L}$ dry NMP and vortex until complete dissolution. Centrifuge the microtube.

5. Mix the two solutions using a micropipet and immediately ad $100 \mu \mathrm{L}$ of $0.1 \mathrm{M}$ aq. $\mathrm{NaHCO}_{3}$ buffer.

6. Vortex for $10 \mathrm{sec}$ and place the microtube at $37^{\circ} \mathrm{C}$ in a microtube heater without agitation for $10 \mathrm{~min}$.

At this point, you can visually check that the reaction occur after five minutes by observing nitrogen bubbles along with elemental Sulphur precipitates within the mixture.

7. Monitor the reaction by RP-HPLC analysis using the following gradient: (Accucore ${ }^{\mathrm{TM}} \mathrm{C} 18$ aQ column, $2.6 \mu \mathrm{m}, 4.6 \times 50 \mathrm{~mm}$ ) with $\mathrm{CH}_{3} \mathrm{CN}$ and $0.1 \%$ aqueous trifluoroacetic acid (aq. TFA, $0.1 \%$, $\mathrm{v} / \mathrm{v}, \mathrm{pH} 2.0$ ) as the eluents [0\% $\mathrm{CH}_{3} \mathrm{CN}(2 \mathrm{~min})$, followed by linear gradient from 0 to $100 \%$ (25

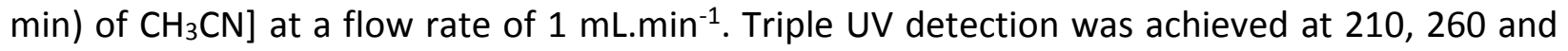
$650 \mathrm{~nm}$ (Fig. 6).

Perform the CUAAC reaction

1. Add $4.6 \mathrm{mg}$ ( $24 \mu \mathrm{mol}, 2$ equivalent) Cul to a 1.5-mL Eppendorf Safe-Lock Tube.

2. Add $100 \mu \mathrm{L}$ dry NMP and vortex.

The Cul is not entirely soluble resulting in a suspension.

3. In one portion, add $21 \mu \mathrm{L}(120 \mu \mathrm{mol}, 10$ equivalents) dry DIEA to the Cul suspension and vortex for $10 \mathrm{~s}$.

4. In one portion, add $6.5 \mathrm{mg}$ ( $24 \mu \mathrm{mol}, 2$ equivalents) biotin alkyne to the Cul suspension and vortex for $10 \mathrm{~s}$.

5. Transfer the sulfo-click crude to the Cul suspension using a micropipet, vortex for $10 \mathrm{sec}$ and place the microtube at $37^{\circ} \mathrm{C}$ in a microtube heater without agitation for $30 \mathrm{~min}$.

At this stage, the Cul catalyst is entirely soluble in the solvent. 
6. Monitor the reaction by RP-HPLC analysis using the following gradient: (Accucore ${ }^{\mathrm{TM}} \mathrm{C} 18 \mathrm{aQ}$ column, $2.6 \mu \mathrm{m}, 4.6 \times 50 \mathrm{~mm}$ ) with $\mathrm{CH}_{3} \mathrm{CN}$ and $0.1 \%$ aqueous trifluoroacetic acid (aq. TFA, $0.1 \%$, $\mathrm{v} / \mathrm{v}, \mathrm{pH} 2.0$ ) as the eluents [ $0 \% \mathrm{CH}_{3} \mathrm{CN}(2 \mathrm{~min}$ ), followed by linear gradient from 0 to $100 \%$ (25 $\min$ ) of $\mathrm{CH}_{3} \mathrm{CN}$ ] at a flow rate of $1 \mathrm{~mL}$. $\mathrm{min}^{-1}$. Triple UV detection was achieved at 210, 260 and $650 \mathrm{~nm}$ (Fig. 6).

7. Take up the crude in a $10 \mathrm{~mL}$ syringe; dilute it by withdrawing $9 \mathrm{~mL}$ of aq. TFA, $0.1 \%$ and purify product on a RP-silica gel column. Eluent: Aq. TFA, 0.1\% / MeCN; 12-g flash column, linear gradient $0->30 \%$ in 40 minutes. Pool fractions containing product and lyophilize.

Alternatively, depending on the synthesis scale envisaged and the material available, the product can be purified via semi-preparative RP-HPLC using the same gradient and eluents.

8. Characterize product 13 by RP-HPLC, ${ }^{1} \mathrm{H}$ NMR, ${ }^{13} \mathrm{C}$ NMR, and HRMS.

Yield of white amorphous powder $9.5 \mathrm{mg}(86 \%) . T_{R}=8.7 \mathrm{~min} .{ }^{1} \mathrm{H} N M R(400 \mathrm{MHz}, D M S O) \delta=1.27-$ $1.62(\mathrm{~m}, 6 \mathrm{H}), 1.80(\mathrm{~s}, 3 \mathrm{H}), 2.07(\mathrm{~s}, 1 \mathrm{H}), 2.11(\mathrm{t}, \mathrm{J}=7.4 \mathrm{~Hz}, 2 \mathrm{H}), 2.57(\mathrm{~d}, \mathrm{~J}=12.3 \mathrm{~Hz}, 1 \mathrm{H}), 2.65-2.78$ $(m, 2 H), 2.79-2.84(m, 1 H), 3.07-3.12(m, 1 H), 3.50-3.64(m, 4 H), 4.08-4.14(m, 3 H), 4.29-4.31(m$, $3 H), 4.43(d, J=2.8 \mathrm{~Hz}, 1 \mathrm{H}), 4.65(d, J=3.6 \mathrm{~Hz}, 1 \mathrm{H}), 5.55-5.58(\mathrm{~m}, 1 \mathrm{H}), 5.75\left(d d, J_{1}=8.2, J_{2}=2.2\right.$ $H z, 1 H), 5.92(d, J=6.4 \mathrm{~Hz}, 1 \mathrm{H}), 6.36(\mathrm{bs}, 1 \mathrm{H}), 6.41(\mathrm{bs}, 1 \mathrm{H}), 6.51(\mathrm{t}, J=6.4 \mathrm{~Hz}, 1 \mathrm{H}), 7.86(\mathrm{~s}, 1 \mathrm{H})$, $8.08(t, J=3.5 \mathrm{~Hz}, 2 \mathrm{H}), 8.32(t, J=5.6 \mathrm{~Hz}, 1 \mathrm{H}), 8.46(t, J=5.6 \mathrm{~Hz}, 1 \mathrm{H}), 11.40(\mathrm{~s}, 2 \mathrm{H}) \mathrm{ppm} .{ }^{13} \mathrm{C} \mathrm{NMR}$ (100.6 MHz, DMSO) $\delta=12.3,25.2,28.0,28.2,33.2,34.1,35.0,36.0,39.9,51.3,55.4,59.2,61.0$, 62.0, 72.8, 73.0, 82.3, 85.9, 88.0, 102.3, 109.8, 122.9, 137.0, 140.6, 145.4, 150.7, 150.9, 162.7, 163.1, 163.8, 169.1, 170.9, $172.1 \mathrm{ppm}$. HRMS (ESI) $\mathrm{m} / \mathrm{z}:[\mathrm{M}+\mathrm{H}]^{+}$Calcd for $\mathrm{C}_{34} \mathrm{H}_{45} \mathrm{~N}_{12} \mathrm{O}_{14} \mathrm{~S}_{2}$ : 909.2620; found 909.2623.

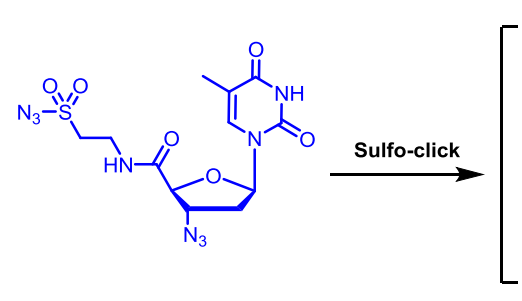

11

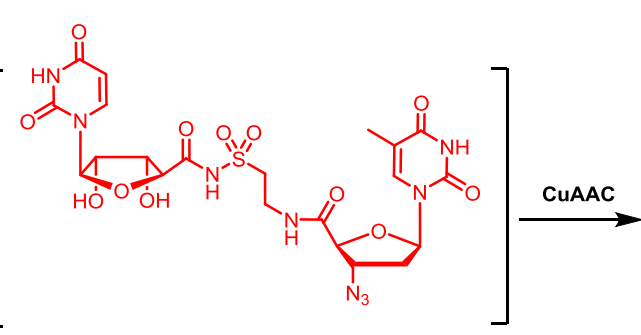

12

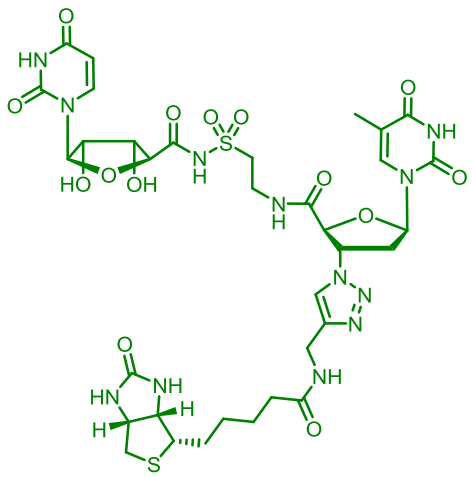

13 


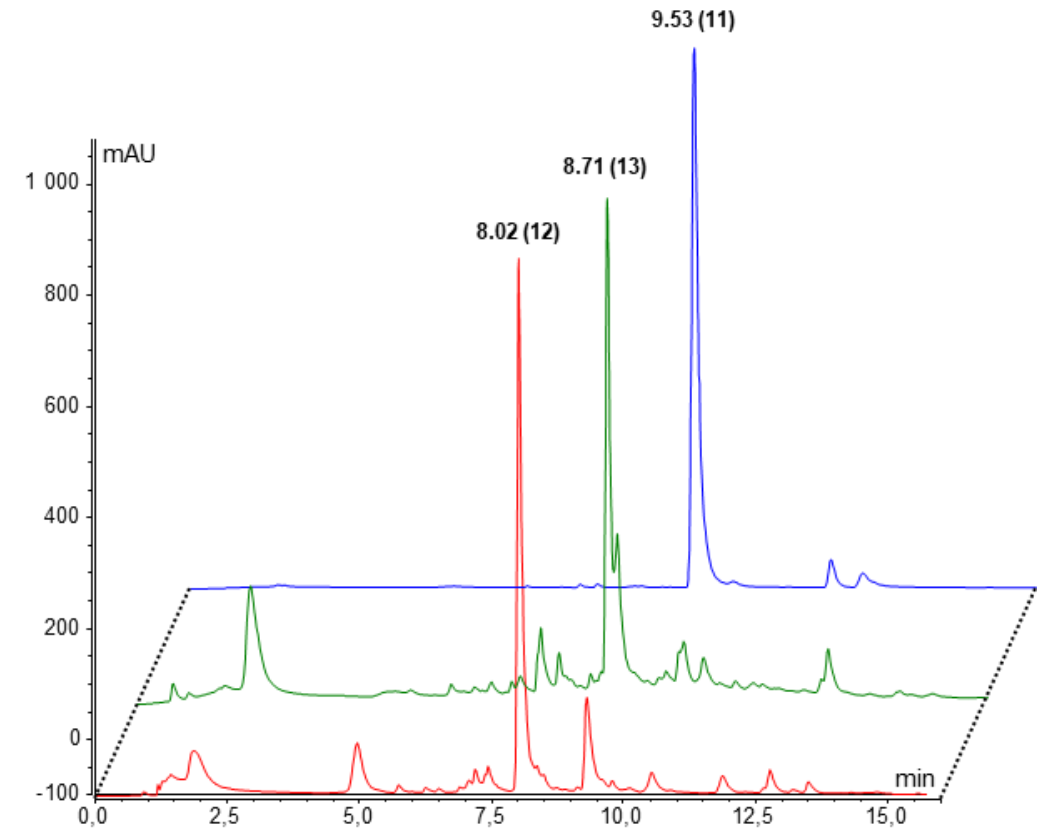

Figure 6 RP-HPLC analyses $(260 \mathrm{~nm})$ of the one-pot double-click conjugations. Analysis of purified compound 11 (in blue); analysis of crude sulfo-click reaction (in red); analysis of crude CuAAC reaction (in green).

\section{COMMENTARY}

\section{BACKGROUND INFORMATION:}

The selective 5' and/or 3' functionalization of ribo- and deoxyribonucleotides is of primary importance for anticancer and antiviral drug development (Jordheim, Durantel, Zoulim, \& Dumontet, 2013). Such modifications are used to enhance the physicochemical properties of the corresponding nucleosides. Thus, many methodologies have been developed over the years to functionalize a nucleoside core with a specific moiety or another biomolecule derivative (e. g. an amino acid, a nucleoside, a carbohydrate, a phospholipid or an alkaloid). Most of the time, reactions that do not meet the criteria of click chemistry are implemented. As illustration, a series of modified nucleosides incorporating zinc-binding pharmacophores as inhibitors of the DNA repair nuclease SNM1A which is responsible for the resistance of certain cancer against traditional DNA crosslinking agents have been synthetized using amide forming coupling reactions and Peterson olefination (Doherty et al., 2019). In another example, dinucleoside analogues were synthetized through a one-pot tandem Staudinger/aza-Wittig/cyclization under microwave irradiation. The dinucleosides obtained containing $(R)$ - or $(S)$-thiazolidin-4-one linkages are active to inhibit HIV reverse transcriptase (Shen et al., 2011). Moreover, in the literature various dinucleoside analogues bearing non-natural linkages have been demonstrated as possible therapeutic agents (Arenas-Jal, Sune-Negre, \& Garcia-Montoya, 2020; Chen et al., 2008). The reactions described above are not compatible with fragile biomolecules and may lack efficiency. Therefore biocompatible click reactions represent a valuable alternative. For instance the CuAAC (Rostovtsev, Green, Fokin, \& Sharpless, 2002; Tornoe, Christensen, \& Meldal, 2002) has been used by several groups to enhance the discovery of new nucleoside analogues with interesting properties (Amblard, Cho, \& Schinazi, 2009; Baraniak, Kacprzak, \& Celewicz, 2011; Baraniak, Ruszkowski, Baranowski, Framski, \& Boryski, 2019; Roy et al., 2011; Sirivolu et al., 2013). The sulfo-click reaction belongs to the class of Thioacid/Azide based Ligation (TAL) reactions. The TAL was originally described as a side reaction in 1980 (Hakimelahi \& Just, 1980) but its potential as an alternative amidation reaction was highlighted more than 20 years later by Williams and co-workers (Kolakowski, Shangguan, Sauers, \& Williams, 2006; Shangguan, Katukojvala, Greenberg, \& Williams, 2003). In particular, they demonstrated that electron-deficient azides readily react with thioacids at room temperature while aliphatic azides require heating at $60^{\circ} \mathrm{C}$ for several hours. In 2010, Liskamp and co-workers denominated "sulfo-click reaction" the specific use of electron-deficient sulfonyl azides in their study devoted to the site specific conjugation of peptides. This designation was subsequently employed in the field of bioconjugation of various classes of molecules (e. g. sugars, peptides, fluorophores or chelators and one example of protein). For instance 1,4,7,10-tetraazacyclododecane-1,4,7,10-tetraacetic acid (DOTA) chelator (Yim et al., 2010) was conjugated to vector 
biomolecules for imaging or treatment of cancer by bounding with radionuclides. An application in the context of peptides coupling was published in 2012 (Raz \& Rademann, 2012), thus illustrating the significance of the reaction for the formation of an amide linkage between the two partners. The sulfo-click reaction was also applied to carbohydrates- and fluorophores-peptides conjugates (Rohmer et al., 2015). A recent example was published concerning its use in the context of radiolabeling by ${ }^{18} \mathrm{~F}$ for positron emission tomography imaging (Urkow, Bergman, \& Wuest, 2019). Noteworthy, perfluoroaryl azides can be an interesting alternative to sulfonyl azides to perform highly efficient conjugation with thioacid derivatives (Xie, Fukumoto, Ramström, \& Yan, 2015). The reaction is equally fast and compatible with aqueous media but the introduction of the perfluoroaryl azide moiety on molecules is tricky and adds a significant steric hindrance. All these examples demonstrate the potential of the sulfo-click as a surrogate click reaction. Indeed, complete conversions are reached within 10 minutes at room temperature in organic or aqueous media using mild conditions. Moreover, the sulfo-click reaction involves unobtrusive polar moieties compared to other click reactions (e.g., cyclooctyne, norbornene, tetrazine, etc.). Despite its significance, the sulfo-click reaction was never applied to nucleic acids. In this context, the protocols presented in this unit describe a straightforward sequence to synthetize $4^{\prime}$-thioacide deoxyribo- and ribonucleosides allowing the implementation of the sulfo-click reaction to nucleoside derivatives in biocompatible aqueous conditions. Moreover, we have developed an efficient procedure allowing the chemoselective one-pot dual functionalization of a bis-azide nucleoside derivative via the sulfo-click and the CuAAC reactions (Clavé et al., 2020). This method has the potential to be applied to any kind of molecules for the development of highly functionalized nucleoside conjugates for various applications.

\section{CRITICAL PARAMETERS AND TROUBLESHOOTING:}

As it is mentioned within the detailed protocols, it may be difficult to reach quantitative conversion during the oxidation of the 5'-OH of nucleosides 1a-d and $\mathbf{1 0}$ using TEMPO/BAIB as oxidant. It is very important to keep the flask opened to ensure oxygen renewal in the solvent. However, complete conversion is always reachable by successive addition of oxidants. The coupling procedures to obtain 3a-d and $\mathbf{1 1}$ in DMF are efficient thanks to the high concentration of the reactants. It is important to perform the five aqueous washings of the AcOEt organic phase to ensure the total elimination of DMF. The TBAF deprotection of 3a-d requires fresh solutions. Indeed, side reactions leading to poor yields have been observed with old solutions. The tetrabutylammonium-thioacetate nucleoside 4 must be stored at $-20^{\circ} \mathrm{C}$ to avoid degradations observed at room temperature.

\section{UNDERSTANDING RESULTS:}

The protocols described in this article allow the preparation of 4'-thioacid-nucleoside derivatives 4 a-d with a straightforward three-step sequence (basic protocol 1). The implementation of the sulfo-click reaction use versatile conditions applicable to numerous polar compounds in aqueous conditions (basic protocol 2) leading to quantitative conversion within ten minutes and high isolated yields $(>75 \%)$. The preparation in two steps of the $3^{\prime}$-azido- $4^{\prime}$-(carboxamido)ethane-sulfonyl azide-3'deoxythymidine 11 (basic protocol 3) allowed the synthesis of the deoxythymidine bis-conjugate 13 (basic protocol 4) using 4'tetrabutylammonium thioacetate-uridine $\mathbf{4 d}$ and the biotin alkyne. The yields of all the reactions in these protocols are good to excellent if correctly executed. The double-click procedure is performed with an excess of one of the partner at each step to ensure quantitative conversions. As indicated Fig. 6, both click reactions are chemoselective and should lead to high isolated yields. Any reduction in yield must be attributed to the purification and freeze-drying stages.

\section{TIME CONSIDERATIONS:}

The synthesis of 4'-tetrabutylammonium thioacetate-nucleoside derivatives $\mathbf{4 a - d}$ starting from 1a-d can be accomplished in one week for each derivative. Each implementation of the sulfo-click reaction can be performed in one working day. Lyophilization of the products 6-8 can be achieved overnight. 3'-azido-4'-(carboxamido)ethane-sulfonyl azide-3'-deoxythymidine $\mathbf{1 1}$ can be prepared in 3-4 days starting from commercially available 3'-azido-3'-deoxythymidine 9. The double-labelling of 3'-azido-4'(carboxamido)ethane-sulfonyl azide-3'-deoxythymidine $\mathbf{1 1}$ via the sulfo-click and the CuAAC reactions is achievable within a day. Lyophilization of the purified final conjugate $\mathbf{1 3}$ can be achieved overnight.

\section{ACKNOWLEDGEMENTS:}

The authors thank the Agence Nationale de la Recherche (ANR "TALAN"-ANR-19-CE07-0004-01) for financial support.

\section{LITERATURE CITED:}


Amblard, F., Cho, J. H., \& Schinazi, R. F. (2009). Cu(I)-Catalyzed Huisgen Azide-Alkyne 1,3-Dipolar Cycloaddition Reaction in Nucleoside, Nucleotide, and Oligonucleotide Chemistry. Chem. Rev., 109, 4207-4220. doi: 10.1021/cr9001462

Arenas-Jal, M., Sune-Negre, J. M., \& Garcia-Montoya, E. (2020). Therapeutic potential of nicotinamide adenine dinucleotide (NAD). [Review]. Eur. J. Pharmacol., 879, 173158. doi: 10.1016/j.ejphar.2020.173158

Baraniak, D., Kacprzak, K., \& Celewicz, L. (2011). Synthesis of 3'-azido-3'-deoxythymidine (AZT)--Cinchona alkaloid conjugates via click chemistry: Toward novel fluorescent markers and cytostatic agents. Bioorg. Med. Chem. Lett., 21, 723-726. doi: 10.1016/j.bmcl.2010.11.127

Baraniak, D., Ruszkowski, P., Baranowski, D., Framski, G., \& Boryski, J. (2019). Nucleoside dimers analogs containing floxuridine and thymidine with unnatural linker groups: synthesis and cancer line studies. Part III. Nucleosides Nucleotides Nucleic Acids, 38, 980-1005. doi: 10.1080/15257770.2019.1641206

Brouwer, A. J., Merkx, R., Dabrowska, K., Rijkers, D. T., \& Liskamp, R. M. (2006). Synthesis and applications of $\beta$-aminoethanesulfonyl azides. Synthesis, 2006, 455-460. doi: 10.1055/s-2006-926273

Chen, L., Petrelli, R., Olesiak, M., Wilson, D. J., Labello, N. P., \& Pankiewicz, K. W. (2008). Bis(sulfonamide) isosters of mycophenolic adenine dinucleotide analogues: inhibition of inosine monophosphate dehydrogenase. Bioorg. Med. Chem., 16, 7462-7469. doi: 10.1016/j.bmc.2008.06.003

Clavé, G., Dursun, E., Vasseur, J. J., \& Smietana, M. (2020). An Entry of the Chemoselective Sulfo-Click Reaction into the Sphere of Nucleic Acids. Org. Lett., 22, 1914-1918. doi: 10.1021/acs.orglett.0c00265

Crich, D., Sana, K., \& Guo, S. (2007). Amino Acid and Peptide Synthesis and Functionalization by the Reaction of Thioacids with 2,4-Dinitrobenzenesulfonamides. Org. Lett., 9, 4423-4426. doi: 10.1021/ol701583t

Doherty, W., Dürr, E.-M., Baddock, H. T., Lee, S. Y., McHugh, P. J., Brown, T., . . McGouran, J. F. (2019). A hydroxamic-acid-containing nucleoside inhibits DNA repair nuclease SNM1A. Org. Biomol. Chem., 17, 8094-8105. doi: 10.1039/c9ob01133a

Epp, J. B., \& Widlanski, T. S. (1999). Facile preparation of nucleoside-5 '-carboxylic acids. J. Org. Chem., 64, 293-295. doi: 10.1021/jo981316g

Hakimelahi, G. H., \& Just, G. (1980). A simple synthesis of 2, 2-disubstituted tetrahydrothiophenes. Tetrahedron Lett., 21, 2119-2122. doi: 10.1016/S0040-4039(00)78973-8

Jordheim, L. P., Durantel, D., Zoulim, F., \& Dumontet, C. (2013). Advances in the development of nucleoside and nucleotide analogues for cancer and viral diseases. Nat. Rev. Drug. Discov., 12, 447-464. doi: 10.1038/nrd4010

Kolakowski, R. V., Shangguan, N., Sauers, R. R., \& Williams, L. J. (2006). Mechanism of Thio Acid/Azide Amidation. J. Am. Chem. Soc., 128, 5695-5702. doi: 10.1021/ja057533y

Merkx, R., Brouwer, A. J., Rijkers, D. T. S., \& Liskamp, R. M. J. (2005). Highly Efficient Coupling of $\beta$ Substituted Aminoethane Sulfonyl Azides with Thio Acids, toward a New Chemical Ligation Reaction. Org. Lett., 7, 1125-1128. doi: 10.1021/ol0501119

Meyer, A., Spinelli, N., Dumy, P., Vasseur, J.-J., Morvan, F., \& Defrancq, E. (2010). Oligonucleotide Sequential Bis-Conjugation via Click-Oxime and Click-Huisgen Procedures. J. Org. Chem., 75, 3927-3930. doi: 10.1021/jo100599m

Patil, S. V., Mane, R. B., \& Salunkhe, M. M. (1994). A Facile Method for Detritylation of 5'-ODimethoxytrityl-3'-O-tert-butyldimethylsilyl-2'-deoxynucleosides. Synth. Commun., 24, 24232428. doi: 10.1080/00397919408010549

Raz, R., \& Rademann, J. (2012). Fmoc-Based Synthesis of Peptide Thioacids for Azide Ligations via 2Cyanoethyl Thioesters. Org. Lett., 14, 5038-5041. doi: 10.1021/ol302247h 
Reisacher, U., Ploschik, D., Rönicke, F., Cserép, G. B., Kele, P., \& Wagenknecht, H.-A. (2019). Copper-free dual labeling of DNA by triazines and cyclopropenes as minimal orthogonal and bioorthogonal functions. Chem. Sci., 10, 4032-4037. doi: 10.1039/C8SC05588B

Rohmer, K., Mannuthodikayil, J., \& Wittmann, V. (2015). Application of the Thioacid-Azide Ligation (TAL) for the Preparation of Glycosylated and Fluorescently Labeled Amino Acids. Isr. J. Chem., 55, 437446. doi: 10.1002/ijch.201500001

Rostovtsev, V. V., Green, L. G., Fokin, V. V., \& Sharpless, K. B. (2002). A Stepwise Huisgen Cycloaddition Process: Copper(I )-Catalyzed Regioselective "Ligation" of Azides and Terminal Alkynes. Angew. Chem., Int. Ed., 41, 2596-2599. doi: 10.1002/1521-3773(20020715)41:14<2596::AIDANIE2596>3.0.CO;2-4

Roy, V., Obikhod, A., Zhang, H. W., Coats, S. J., Herman, B. D., Sluis-Cremer, N., . . Schinazi, R. F. (2011). Synthesis and anti-HIV evaluation of 3 '-triazolo nucleosides. Nucleosides Nucleotides Nucleic Acids, 30, 264-270. doi: 10.1080/15257770.2011.580291

Schoch, J., Staudt, M., Samanta, A., Wiessler, M., \& Jäschke, A. (2012). Site-specific one-pot dual labeling of DNA by orthogonal cycloaddition chemistry. Bioconjugate Chem., 23, 1382-1386. doi: 10.1021/bc300181n

Shangguan, N., Katukojvala, S., Greenberg, R., \& Williams, L. J. (2003). The Reaction of Thio Acids with Azides: A New Mechanism and New Synthetic Applications. J. Am. Chem. Soc., 125, 7754-7755. doi: $10.1021 / j a 0294919$

Shen, F., Li, X., Zhang, X., Yin, Q., Qin, Z., Chen, H., . . Ma, Z. (2011). Microwave-assisted synthesis of dinucleoside analogues containing a thiazolidin-4-one linkage via one-pot tandem Staudinger/aza-Wittig/cyclization. Org. Biomol. Chem., 9, 5766-5772. doi: 10.1039/c1ob05675a

Sirivolu, V. R., Vernekar, S. K., Ilina, T., Myshakina, N. S., Parniak, M. A., \& Wang, Z. (2013). Clicking 3'azidothymidine into novel potent inhibitors of human immunodeficiency virus. J. Med. Chem., 56, 8765-8780. doi: 10.1021/jm401232v

Tornoe, C. W., Christensen, C., \& Meldal, M. (2002). Peptidotriazoles on Solid Phase: [1,2,3]-Triazoles by Regiospecific Copper(I)-Catalyzed 1,3-Dipolar Cycloadditions of Terminal Alkynes to Azides. J. Org. Chem., 67, 3057-3064. doi: 10.1021/jo011148j

Urkow, J., Bergman, C., \& Wuest, F. (2019). Sulfo-click chemistry with 18F-labeled thio acids. Chem. Commun., 55, 1310-1313. doi: 10.1039/c8cc08717b

Winz, M.-L., Linder, E. C., Becker, J., \& Jäschke, A. (2018). Site-specific one-pot triple click labeling for DNA and RNA. Chem. Commun., 54, 11781-11784. doi: 10.1039/c8cc04520h

Xie, S., Fukumoto, R., Ramström, O., \& Yan, M. (2015). Anilide Formation from Thioacids and Perfluoroaryl Azides. J. Org. Chem., 80, 4392-4397. doi: 10.1021/acs.joc.5b00240

Yim, C.-B., Dijkgraaf, I., Merkx, R., Versluis, C., Eek, A., Mulder, G. E., . . Liskamp, R. M. J. (2010). Synthesis of DOTA-Conjugated Multimeric [Tyr3]Octreotide Peptides via a Combination of $\mathrm{Cu}(\mathrm{I})$-Catalyzed "Click" Cycloaddition and Thio Acid/Sulfonyl Azide "Sulfo-Click" Amidation and Their in Vivo Evaluation. J. Med. Chem., 53, 3944-3953. doi: 10.1021/jm100246m

Zhu, X.-F., Williams, H. J., \& Scott, A. I. (2000). Facile and highly selective 5'-desilylation of multisilylated nucleosides. J. Chem. Soc., Perkin Trans. 1, 2305-2306. doi: 10.1039/b003562i 